\title{
Galvanic current activates the NLRP3 inflammasome to promote type I collagen production in tendon
}

\begin{abstract}
Alejandro Peñín-Franch ${ }^{1}$, José Antonio García-Vidal ${ }^{1,2}$, Carlos Manuel Martínez ${ }^{1}$, Pilar Escolar-Reina ${ }^{1,2}$, Rosa M. Martínez-Ojeda ${ }^{3}$, Ana I.Gómez ${ }^{1}$, Juan M. Bueno ${ }^{3}$, Francisco Minaya-Muñoz ${ }^{4,5}$, Fermín Valera-Garrido ${ }^{4,5,6}$, Francesc Medina-Mirapeix ${ }^{1,2}$, Pablo Pelegrín ${ }^{1,7}$
\end{abstract}

${ }^{1}$ Instituto Murciano de Investigación Biosanitaria IMIB-Arrixaca, Hospital Clínico Universitario Virgen de la Arrixaca, 30120 Murcia, Spain.

${ }^{2}$ Department of Physical Therapy, University of Murcia, 30100 Murcia, Spain.

${ }^{3}$ Laboratorio de Óptica, Instituto Universitario de Investigación en Óptica y Nanofísica, Universidad de Murcia, 30100 Murcia, Spain.

${ }^{4}$ MVClinic Institute, 28600 Madrid, Spain.

${ }^{5}$ CEU San Pablo University, 28925 Madrid, Spain.

${ }^{6}$ Invasive Physiotherapy Department, Getafe C.F., 28903 Madrid, Spain.

${ }^{7}$ Department of Biochemistry and Molecular Biology B and Immunology, University of Murcia, 30120 Murcia, Spain.

Corresponding author: Dr. Pablo Pelegrín. Edificio LAIB 4ª Planta, Instituto Murciano de Investigación Biosanitaria (IMIB-Arrixaca). Carretera Buenavista s/n. 30120 El Palmar, Murcia, Spain. Phone: +34 868885 038; e-mail: pablo.pelegrin@imib.es

RUNNING TITTLE: Galvanic current activates NLRP3.

KEYWORDS: Percutaneous needle electrolysis, tendon, tendinopathy, inflammasome, IL-1 $\beta$, NLRP3, caspase-1, pyroptosis. 


\section{ABSTRACT}

29 The NLRP3 inflammasome coordinates inflammation in response to different 30 pathogen- and damage-associated molecular patterns, being implicated in different 31 infectious, chronic inflammatory, metabolic and degenerative diseases. In chronic 32 tendinopathic lesions, different non-resolving mechanisms produce a degenerative 33 condition that impairs tissue healing and which therefore complicates their clinical 34 management. Percutaneous needle electrolysis consists of the application of a 35 galvanic current and is an emerging treatment for tendinopathies. In the present study, 36 we found that galvanic current activates the NLRP3 inflammasome and induces an 37 inflammatory response that promotes a collagen-mediated regeneration of the tendon 38 in mice. This study establishes the molecular mechanism of percutaneous electrolysis 39 that can be used to treat chronic lesions and describes the beneficial effects of an 40 induced inflammasome-related response. 


\section{INTRODUCTION}

42 Galvanic current applied using a percutaneous needle is an emerging and minimally invasive technique that seeks to regenerate damaged tissues (Valera-Garrido et al., 2014). The needle used to apply galvanic current is guided, using ultrasound equipment, into affected soft tissues by direct visualization and therefore is able to stimulate locally the cells in the damaged area. Percutaneous needle electrolysis consists of applying a galvanic current through an acupuncture needle and thus combining mechanical and electrical stimulation of the tissue that results in a local controlled microtrauma. This microtrauma in turn generates a local inflammatory response that makes possible and fosters the repair of the affected tissue (ValeraGarrido and Minaya-Muñoz, 2019). Galvanic current has been successfully used to repair chronic non-resolving lesions, such as tendinopathies developed after prolonged extreme exercise, which often establish a degenerative condition of the tissue that impairs healing and complicates clinical management (Cook and Purdam, 2009; Regan et al., 1992; Soslowsky et al., 2000). In randomized trials, anti-inflammatory therapies have shown to be ineffectual at treating these types of lesion (Bisset et al., 2006; Coombes et al., 2013) and application of galvanic currents by percutaneous needle alone has been found sufficient when it comes to regenerating the tissue (Bubnov, 2013; Chellini et al., 2019; De-la-Cruz-Torres et al., 2020; Margalef et al., 2020; ValeraGarrido et al., 2020, 2014, 2013).

Resolving inflammation promotes a response that recovers homeostasis by repairing tissues (Medzhitov, 2008). However, chronic non-resolving inflammation can induce continuous tissue regeneration and excessive accumulation of extracellular matrix components, which in turn leads to fibrosis of soft tissues (Alegre et al., 2017; 65 Borthwick et al., 2013; Gaul et al., 2020; Wynn, 2008). Therefore, a balanced inflammatory response is required to recover homeostasis and successfully heal tissue

67 (Borthwick et al., 2013; Eming et al., 2017; Liston and Masters, 2017; Medzhitov, 2008). In response to tissue damage, the nucleotide-binding oligomerization domain 
with leucine rich repeat and pyrin domain containing 3 (NLRP3) inflammasome is specifically activated over other inflammatory pathways and coordinates an inflammatory response (Broz and Dixit, 2016; Schroder et al., 2011). NLRP3 inflammasome is a multiprotein complex induced in myeloid cells after the detection of damage- or pathogen-associated molecular patterns, including elevated concentrations of extracellular ATP, changes in extracellular osmolarity or detection of insoluble particles and crystals, such as uric acid crystals or amyloid deposition (Amores-Iniesta et al., 2017; Compan et al., 2012; Heneka et al., 2013; Mayor et al., 2006). These triggers specifically induce NLRP3 activation over other inflammasomes as they decrease intracellular $\mathrm{K}^{+}$concentration resulting in conformational change of NLRP3 structure and, therefore, active NLRP3 oligomers (Muñoz-Planillo et al., 2013; TapiaAbellán et al., 2021). Active NLRP3 oligomers recruit the accessory apoptosis-specklike protein with a caspase recruitment and activation domain (ASC) that favors the activation of the inflammatory caspase-1 (Boucher et al., 2018; Li et al., 2018; Schmidt et al., 2016). Caspase-1 proteolytically processes immature pro-inflammatory cytokines of the interleukin (IL)-1 family to produce the bioactive form of IL-1 $\beta$ and IL-18 (Broz and Dixit, 2016; Schroder et al., 2011). Caspase-1 also processes gasdermin D protein (GSDMD), and its amino-terminal fragment $\left(G S D M D^{N T}\right)$ oligomerizes in the plasma membrane forming pores, thus releasing IL-1 $\beta$ and IL-18 cytokines, as well as other intracellular content, including inflammasome oligomers (Baroja-Mazo et al., 2014; Broz et al., 2020).

Prolonged NLRP3 activation occurs in different chronic inflammatory, metabolic and degenerative diseases such as gout, type 2 diabetes or Alzheimer (Daniels et al., 2016; Heneka et al., 2013; Masters et al., 2010; Mayor et al., 2006), therefore selective small molecules that block NLRP3 are emerging as novel anti-inflammatory therapies (Cocco et al., 2017; Coll et al., 2015; Tapia-Abellán et al., 2019). However, in some pathological circumstances, a boost, rather than an inhibition, of NLRP3 would be more beneficial for reducing clinical complications, such as in immunosuppressed septic 
97 patients, who have high mortality rates due to secondary infections associated with a 98 profound deactivation of the NLRP3 inflammasome (Martínez-García et al., 2019).

99 The detailed molecular mechanism behind percutaneous needle electrolysis inducing 100 an inflammatory response has not been yet described, so we studied if NLRP3 101 inflammasome could be activated via galvanic currents and if doing so would lead to 102 tissue regeneration. We found that applying galvanic current via percutaneous needle 103 electrolysis activated the NLRP3 inflammasome and induced the release of IL-1 $\beta$ and 104 IL-18 from macrophages. Mice deficient in NLRP3 failed to increase IL-1 $\beta$ in tendons 105 after percutaneous needle electrolysis and ended up with reduced TGF- $\beta$ and type I 106 collagen deposition with high dispersion of collagen fibers, which in turn resulted in 107 tendons with decreased resistance. All this indicates that the NLRP3 inflammasome 108 plays an important role in the regenerative response of the tendon after application of 109 therapeutically percutaneous needle electrolysis. 


\section{RESULTS}

111 Galvanic current enhances macrophage pro-inflammatory M1 phenotype

112 We initially designed and produced a device to apply galvanic current to adherent 113 cultured cells in 6-well cell-culture plates (Figure 1-Figure supplement 1), this 114 device allowed us to explore the effect of galvanic currents in mouse macrophages 115 derived from bone marrow. Applying $12 \mathrm{~mA}$ of galvanic current twice for 6 seconds 116 each time to LPS stimulated macrophages increase the expression of Cox2 and II6 117 genes (Figure 1A). However, it did not affect LPS-induced $/ / 1 b$ or Tnfa pro118 inflammatory gene expression (Figure 1A). Interestingly meanwhile Tnfa expression 119 was upregulated with galvanic current alone (Figure 1A), galvanic currents did not 120 induce the expression of Cox2, $/ 16$ or $/ / 1 b$ genes on non-LPS treated macrophages, or over IL-4 treated macrophages (Figure 1A). When macrophages were polarized to M2

122 by IL-4, galvanic currents decreased the expression of the M2 markers Arg1, Fizz1 and 123 Mrc1 (Figure 1B); however, this decrease was small and non-significant for the M2 124 marker $Y m 1$ (Figure 1B). These data suggest that galvanic current could enhance the 125 pro-inflammatory signature of M1 macrophages whilst decreasing M2 polarization. We 126 next studied the concentration of released pro-inflammatory cytokines from 127 macrophages, and found that galvanic current did not increase the concentration of IL1286 or TNF- $\alpha$ released after LPS stimulation (Figure 1C), but that it did significantly 129 augment the release of $\mathrm{IL}-1 \beta$ in an intensity dependent manner (Figure 1C). These 130 data indicate that the increase in $/ / 6$ and Tnfa gene expression detected at mRNA level 131 does not transcribe to higher release of IL-6 and TNF- $\alpha$ over LPS treatment, but that 132 galvanic current could potentially activate an inflammasome that induces the release of $133 \mathrm{IL}-1 \beta$. 
136 Given that IL-1 $\beta$ release is increased by the activation of caspase- 1 after the canonical

137 or non-canonical formation of inflammasome (Broz and Dixit, 2016), we next studied

138 the release of IL-1 $\beta$ induced by galvanic current in macrophages deficient in caspase-1

139 and -11 to avoid both the canonical and non-canonical inflammasome signaling. We

140 found that Casp $1 / 11^{-/-}$macrophages fail to release IL-1 $\beta$ induced by galvanic current

141 (Figure 2A). We then found that applying galvanic current to Pycard ${ }^{/-}$macrophages

142 also failed to induce the release of $\mathrm{IL}-1 \beta$, which indicated that the inflammasome

143 adaptor protein ASC is also needed to activate the inflammasome (Figure 2A). Since

144 applying current could be considered a sterile danger signal, we next assessed the role

145 of NLRP3 as an inflammasome sensor important for eliciting an immune response in 146 sterile dangerous situations (Broz and Dixit, 2016; Liston and Masters, 2017). NIrp3 ${ }^{-/}$

147 and the use of the specific NLRP3 inhibitor MCC950 (Coll et al., 2015; Tapia-Abellán et 148 al., 2019) impaired the release of IL-1 $\beta$ induced by galvanic current (Figure $2 \mathbf{A}, \mathbf{B}$ ), 149 demonstrating that the NLRP3 inflammasome is activated when galvanic current is 150 applied. Similarly, galvanic current was also able to induce the release of IL-18 (Figure 151 2C), another cytokine dependent on the activation of the inflammasome. The use of 152 MCC950 or macrophages deficient in NLRP3 failed to release IL-18 after galvanic 153 current was applied (Figure 2C), which confirms that galvanic current stimulates 154 NLRP3 to induce the release of both IL-1 $\beta$ and IL-18. Similar results were obtained with 155 controls using the specific NLRP3 activator nigericin (Figure 2B and Figure 2-Figure supplement 1A). Mechanistically, the use of an extracellular buffer with $40 \mathrm{mM}$ of $\mathrm{KCl}$ decreased IL-1 $\beta$ release induced by nigericin and galvanic current application, but not the release of IL-1 $\beta$ induced by Clostridium difficile toxin $B$, which activates the Pyrin inflammasome, which is a $\mathrm{K}^{+}$-efflux independent inflammasome (Figure 2D). However, two pulses of $12 \mathrm{~mA}$ of galvanic current for 6 seconds failed to decrease intracellular $\mathrm{K}^{+}$

161 (Figure 2E, Figure 2-Figure supplement 1B), but increasing the number of pulses 162 of galvanic current to eight did result in a significant decrease of intracellular $\mathrm{K}^{+}$(Figure 
2E). These data suggest that galvanic current slightly decreases intracellular $\mathrm{K}^{+}$when compared to the application of the $\mathrm{K}^{+}$ionophore nigericin (Figure 2E) and this explains the smaller concentration of IL-1 $\beta$ that is released by galvanic current compared to nigericin application (Figure 2B). After applying galvanic current we were able to detect the generation of the active p20 caspase- 1 fragment, and processed IL-1 $\beta$ and GSDMD $^{\mathrm{NT}}$ (Figure 2F). MCC950 was able to abrogate caspase-1 activation and the processed forms of $\mathrm{IL}-1 \beta$ and GSDMD $^{\mathrm{NT}}$ (Figure 2F), which suggests functional activation of caspase- 1 and downstream signaling because of the activation of canonical NLRP3 and rules out the non-canonical NLRP3 activation that would result in

172 GSDMD processing in the presence of MCC950. To ensure that the galvanic current 173 really was activating NLRP3, we used HEK293T cells that were stably expressing 174 NLRP3-YFP protein, a method widely used to assess NLRP3 activation (Chen and 175 Chen, 2018; Compan et al., 2012; Tapia-Abellán et al., 2021, 2019). Fluorescence microscopy showed that 2 impacts of $12 \mathrm{~mA}$ of galvanic current for 6 seconds induced

177 the formation of an intracellular NLRP3-YFP punctum, which was inhibited by the application of MCC950 (Figure 2G). All these data confirm that galvanic current activates the NLRP3 inflammasome, and since NLRP3 deficient macrophages failed to release IL-1 $\beta$ or IL-18, that no other inflammasome expressed in the macrophages was being activated.

\section{Galvanic current does not induce inflammasome-mediated pyroptosis}

184 Given that GSDMD was processed and the N-terminus was detected after the application of galvanic current, we next assessed pyroptosis by means of Yo-Pro-1 uptake in cells to measure plasma membrane pore formation and cell viability, and

187 LDH leakage from the cell to determine plasma membrane damage. Two impacts of 188 galvanic currents of different intensities $(3,6,12 \mathrm{~mA})$ for a period of 6 seconds 189 (conditions that induce IL-1 $\beta$ release as we show in Figure 1C) only induced a slight 
190 increase in cell death (Figure 3A). This increase in cell death was not associated with

191 the activation of the inflammasome given that it was also present in macrophages

192 deficient in NLRP3, ASC or caspase-1/11 (Figure 3B), which in turn suggests that it 193 occurred independently of inflammasome-mediated pyroptosis. Increasing the number 194 or the length of time of $12 \mathrm{~mA}$ impacts of galvanic current on macrophages, resulted in 195 a time-dependent increase in cell death (Figure 3A), which correlates with higher 196 concentrations of IL-1 $\beta$ and IL-18 release (Figure 3C). However, whereas IL-1 $\beta$ and IL19718 release was blocked by MCC950 (Figure 3C), LDH release was not dependent on 198 NLRP3 activation (Figure 3D). This further corroborates the fact that the NLRP3 199 activation is dependent on the intensity and time of galvanic current application. 200 Similarly, two impacts of $12 \mathrm{~mA}$ for a period of 6 seconds were unable to induce 201 plasma membrane permeabilization measured in terms of Yo-Pro-1 uptake during a period of $3 \mathrm{~h}$ (Figure 3E). Yo-Pro uptake increased over $3 \mathrm{~h}$ in an intensity dependent manner $(3,6,12 \mathrm{~mA})$ when 8 impacts were applied for 6 seconds (Figure 3E). This increase in plasma membrane permeabilization was not reversed after NLRP3 was blocked with MCC950 or when ASC-deficient macrophages were used (Figure 3F). All these results demonstrate that doses of 3 or $6 \mathrm{~mA}$ of galvanic current for impacts of 6 seconds do not compromise cell viability but are still able to induce an inflammatory response dependent on NLRP3 activation, in contrast to current intensities of $12 \mathrm{~mA}$ which, if prolonged cause significant cell death independently of the inflammasome.

211 Galvanic current applied in tendon increases inflammation in vivo

212 When studying the effect of galvanic current in vivo, we found that application of 3 213 impacts of $3 \mathrm{~mA}$ of galvanic current for 3 seconds in the calcaneal tendon of mice 214 increased the number of polymorphonuclear cells after 3 days when compared with tendons treated with needling alone (a puncture without current application, Figure

216 4A,B). This increase returned to basal after 7 days and stayed low up to 21 days after 217 galvanic current application (Figure 4B). Similarly, the number of F4/80 $0^{+}$macrophages 
218 increased 3 days after the application of galvanic current when compared to needling 219 alone and returned to basal levels after 7 days (Figure 4C,D). Other immune cell types 220 detected in the tendon, such as mastocytes, were not significantly increased by 221 galvanic current when compared to needling alone (Figure 4-Figure supplement 222 1A). Given that polymorphonuclear cells increased in a similar manner to 223 macrophages, we then aimed to investigate if galvanic current might also induce the 224 release of IL-1 $\beta$ from neutrophils. However, the application of galvanic current to LPSprimed neutrophils failed to release IL-1 $\beta$ or LDH (Figure 4-Figure supplement 1B).

226 Other histological features of the tendon (general structure of the tendon, number of 227 tenocytes, shape and area of tenocyte nuclei or neo-vascularization) were also 228 unaffected by the application of galvanic currents compared to needling alone (Figure 4-Figure supplement $1 \mathrm{C}-\mathrm{G}$ ).

We next assessed the expression of different pro-inflammatory cytokines in the calcaneal tendon 3 days after 3 impacts of $3 \mathrm{~mA}$ of galvanic current application for 3 seconds to characterize the molecular inflammatory response in the tendon.

233 Expression of $/ / 6$, $/ / 1 a$ and $/ / 1 b$, as well as the IL-1 receptor antagonist $(/ / 1 r n)$ and the 234 chemokine $\mathrm{Cxc} / 10$ all increased after percutaneous electrolysis when compared to needling alone (Figure 5A). However, as shown in Figure 1 the increase in $1 / 6$ cytokine gene expression induced by galvanic current in macrophages did not correlate with an increase in IL-6 cytokine secretion. Different NLRP3 inflammasome genes also exhibit an increase in expression (NIrp3, Pycard, Casp1) when galvanic current was applied, but this increase was not significant when compared to needling (Figure 5B). Gsdmd expression was not upregulated in the tendons after galvanic current application

241 (Figure 5B). These data suggest that galvanic current induces an inflammatory 242 response driven by the infiltration of polymorphonuclear cells and macrophages, 243 together with an increase in the expression of several cytokines and chemokines. 
247 In order to evaluate if the NLRP3 inflammasome mediates the inflammatory response

248 in tendons after percutaneous electrolysis, we applied galvanic currents to the calcaneal tendon of $\mathrm{NIrp3}^{-/}$mice. Application of 3 impacts of $3 \mathrm{~mA}$ of galvanic current

250 for 3 seconds in the calcaneal tendon of $\mathrm{NIrp3}^{-/}$mice resulted in a significant reduction

251 of $\|/ 1 b,\| / 1 \mathrm{rn}$ and $\mathrm{Cxc} / 10$ expression after 3 days when compared to wild-type mice

252 (Figure 6A). Specific inflammasome associated genes, such as Pycard, Casp1 or Gsdmd (except for NIrp3) did not affect their expression in the calcaneal tendon of $\mathrm{NIrp3}^{-/}$mice 3 days after the application of galvanic current when compared to wild type mice (Figure 6B). Surprisingly, galvanic current tended to increase both the expression of $/ 16$ in the tendons of $\mathrm{NIrp3}^{-/}$after 3 days (Figure $6 \mathrm{C}$ ) and the number of polymorphonuclear cells (Figure 6D). However, the number of macrophages was not affected in the $\mathrm{NIrp3}^{-/}$calcaneal tendon when galvanic current was applied (Figure 6D). We also confirmed a decrease in $/ / 1 b$ and $C x c / 10$ expression in the tendons of Pycard $^{1-}$ mice 3 days after the application of galvanic current (Figure 6-Figure supplement $\mathbf{1 A}, \mathbf{B})$, which suggests that the NLRP3 inflammasome is important in modulating part of the inflammatory response after the application of galvanic current.

The NLRP3 inflammasome induces a tissue regenerative response to galvanic current application that increases tendon stiffness

Galvanic current application has been widely used to resolve chronic tendinopathies in different tendons (Abat et al., 2016; Rodríguez-Huguet et al., 2020; Valera-Garrido et al., 2014), and as an example we present here a case where lateral epicondylitis was resolved in six weeks after four sessions of percutaneous electrolysis through the application of $3 \mathrm{~mA}$ of galvanic current for 3 periods of 3 seconds (3:3:3) (Figure 7-

271 Figure supplement 1A), in accordance with the clinical protocol previously described 272 by Valera-Garrido and Minaya-Muñoz (Valera-Garrido and Minaya-Muñoz, 2016). 
273 During tissue regeneration, the production of new extracellular matrix through collagen

274 deposition is a key process (Shook et al., 2018; Wynn, 2008). In order to determine if

275 the inflammatory response mediated by the NLRP3 inflammasome after galvanic

276 current application is important for tissue regeneration, we measured Tgfb1 expression

277 as a key factor in inducing collagen production. We found that in vivo the expression of

278 Tgfb1 3 days after the application of galvanic current in the calcaneal tendon of mice

279 was dependent on NLRP3 (Figure 7A). Likewise, after 7 days of percutaneous

280 electrolysis the levels of type III collagen were decreased, with a parallel increase in

281 type I collagen when compared to needling alone (Figure 7B, Figure 7-Figure

282 supplement 1D). However, percutaneous electrolysis did not affect collagen fiber

283 properties (width or length) when compared to needling alone (Figure 7-Figure

supplement 1B,C). The increase in type I collagen 7 days after galvanic current application was reduced in $\mathrm{NIrp3}^{--}$mice (Figure 7C). NLRP3 also controlled the structural dispersion of collagen fibers, which was decreased by galvanic current application in wild type mice, but increased in $\mathrm{NIrp3}^{/-}$mice (Figure 7D, Figure 7-

Figure supplement 1E). All these results suggest that the NLRP3 inflammasome controls the response of galvanic current thus inducing type I collagen production and arranging the collagen fibers. This controlled deposition of collagen fibers induced by galvanic current increased tendon stiffness and decreased the maximum tension supported by the tendon (Figure 7E). NLRP3 inflammasome was responsible for increased tendon stiffness after galvanic current application (Figure 7E). Overall, we found that the application of galvanic current is able to activate the NLRP3 inflammasome and induce the release of $\mathrm{IL}-1 \beta$, thus initiating an inflammatory response that regenerates the tendon by increasing type I collagen, arranging the collagen fibers and increasing the resistance of the tendon to changes in length 


\section{DISCUSSION}

300 In this study we demonstrate how the application of galvanic current induces in macrophages a pro-inflammatory signature, mainly characterized by the activation of the NLRP3 inflammasome and the release of mature $\mathrm{IL}-1 \beta$ and $\mathrm{IL}-18$. This is in agreement with the fact that the NLRP3 inflammasome is a key pathway for controlling inflammation in the absence of pathogenic microorganisms (in sterile conditions) by executing a pro-inflammatory type of cell death called pyroptosis (Broz et al., 2020; Broz and Dixit, 2016; Liston and Masters, 2017). Here we found that galvanic current application, a technique that has been widely used to resolve chronic lesions in humans (Valera-Garrido et al., 2014), was able to activate the NLRP3 inflammasome and induce IL-1 $\beta$ and IL-18 release, but with very little associated pyroptotic cell death. This could be due to two potentially different mechanisms: $(i)$ that after galvanic current application an alternative means of processing GSDMD occurs which is independent of NLRP3 and which could inactivate its N-terminal lytic domain, as has been previously found for caspase-3 processing GSDMD (Taabazuing et al., 2017); and/or (ii) that the small amounts of GSDMD ${ }^{\mathrm{NT}}$ found could create a small number of pores in the plasma membrane, thus facilitating their repair by the endosomal sorting complexes required for transport machinery, which in turn leads to an hyperactive state of the macrophage

317 (Evavold et al., 2018; Rühl et al., 2018). During this state of the macrophage, IL-1 $\beta$ is released in the absence of cell death (Evavold et al., 2018). However, an increase in the intensity and the time of galvanic current application leads to an increase in cell death that was independent of the inflammasome and could be related to the technique per se. Therefore, clinical application of current intensities above $6 \mathrm{~mA}$ would probably

322 lead to necrosis of the tissue and not to an efficient reparative process. Galvanic 323 currents of 3 and $6 \mathrm{~mA}$ for 2 impacts of 6 seconds are both able to induce NLRP3 324 inflammasome activation in vitro and lead to phenotypic changes in the tendon in vivo. 325 This is in line with the fact that $3 \mathrm{~mA}$ of galvanic current is able to induce a clinically 
326 significant regeneration of lesions (García Vidal et al., 2019; Margalef et al., 2019;

327 Medina i Mirapeix et al., 2019; Valera-Garrido et al., 2014). High intensity doses for

328 long periods of time or repeated impacts could induce massive tissue necrosis and are

329 therefore not recommended for clinical practice.

330 The activation of the NLRP3 inflammasome induced by galvanic currents was found to

331 be dependent on $\mathrm{K}^{+}$efflux, because extracellular high concentrations of $\mathrm{K}^{+}$were able to

332 block IL-1 $\beta$ release, and high intensities of galvanic current decreased intracellular $\mathrm{K}^{+}$.

333 This is similar to the effect of the well-studied $\mathrm{K}^{+}$ionophore nigericin, which

334 dramatically decreases intracellular $\mathrm{K}^{+}$and releases IL-1 $\beta$ (Muñoz-Planillo et al., 2013;

335 Petrilli et al., 2007; Próchnicki et al., 2016). In fact, the amount of IL-1 $\beta$ released from

336 galvanic current activated macrophages was lower than when macrophages were

337 activated with nigericin, which suggests that the NLRP3 activation is correlated with the

338 decrease in intracellular $\mathrm{K}^{+}$(Tapia-Abellán et al., 2021). The low NLRP3 activation

339 induced by galvanic current application could result in a moderate inflammatory

340 response in vivo that is beneficial for tissue regeneration. In fact, NLRP3 was important

341 for inducing an inflammatory response in vivo with increased quantities of different

342 cytokines including $/ / 1 \mathrm{~b}$ or $\mathrm{Cxc} / 10$, that conditioned the structure and functions of the

343 treated tendons. However, NLRP3 deficiency does not affect $/ 16$ production or the

344 infiltration of polymorphonuclear cells when galvanic currents are applied in vivo. This

345 shows that NLRP3 induced by galvanic current is able to control a specific

346 inflammatory program in vivo, but it probably do not affect the IL-6-mediated infiltration

347 of polymorphonuclear cells in tendons.

348 Exacerbated NLRP3 activation could led to fibrosis (Alegre et al., 2017; Gaul et al., 349 2020), which suggests that NLRP3 could control collagen deposition. The mild 350 activation of NLRP3 found after galvanic current application was associated with 351 increased production of Tgfb1, an increase in collagen type I vs type III in tendons, and 352 reduced structural dispersion of collagen fibers. This is associated with an increase in 
353 tendon stiffness, which is related to the resistance of the tendon to changes in length,

354 with tendon stiffness being reduced during ageing and resulting in weaker tendons 355 (Krupenevich et al., 2021). This could explain previous clinical findings relating to 356 galvanic current therapy, such as the fact that almost all patients treated with galvanic current in tendon lesions had no relapses at long term (Valera-Garrido et al., 2014) and

358 the fact that application of galvanic current in human tendon lesions in combination 359 with exercise therapy achieved greater functional recovery compared to exercise alone 360 (Moreno et al., 2017), and also compared to the combination of exercise with other 361 rehabilitation interventions such as electrotherapy or mechanical intervention (Abat et 362 al., 2016; Rodríguez-Huguet et al., 2020). Thus, our findings could professionals to 363 choose and combine rehabilitative and orthopedic treatments. However, a limitation of our study is that using animals restricts us to employing the ultrasound-guided puncture when applying galvanic current to the calcaneal tendon of mice, because it is the largest accessible tendon, whereas in humans galvanic current has been applied supraspinatus (Rodríguez-Huguet et al., 2020), patellar (Abat et al., 2016) and lateral epicondyle (Valera-Garrido et al., 2014) tendons. In all tendons, applying galvanic current application was found to have a similar clinical benefit, but we cannot rule out the fact that the calcaneal tendon of mice would present a different response to

371 galvanic current. In fact, different species have been reported to have different 372 inflammatory tenocyte responses (Oreff et al., 2021), and although mice and humans 373 present high overall similarities in their tenocyte responses (Oreff et al., 2021), it is 374 necessary to apply galvanic current in the presence of specific NLRP3 blockers, such as MCC950, in additional animal models with species other than mice.

376 Therefore, this study reports how galvanic current is a feasible technique applied in

377 vivo to activate the NLRP3 inflammasome and induce a local inflammatory response to 378 enhance a collagen-mediated regeneration process in the tendon, establishing the 379 molecular mechanism of percutaneous electrolysis for the treatment of chronic lesions. 
381 Key Resources Table

\begin{tabular}{|c|c|c|c|c|}
\hline $\begin{array}{l}\text { Reagent } \\
\text { type } \\
\text { (species) } \\
\text { or } \\
\text { resource }\end{array}$ & $\begin{array}{l}\text { Designati } \\
\text { on }\end{array}$ & $\begin{array}{l}\text { Source or } \\
\text { reference }\end{array}$ & Identifiers & $\begin{array}{l}\text { Additiona } \\
\text { I } \\
\text { informati } \\
\text { on }\end{array}$ \\
\hline $\begin{array}{l}\text { Genetic } \\
\text { reagent } \\
\text { (Mus } \\
\text { musculus, } \\
\text { male) }\end{array}$ & $\begin{array}{l}\text { NLRP3- } \\
\text { deficient } \\
\text { mice } \\
(\text { Nlrp3 } \\
\text { C5 })- \\
\text { C57 BL/6 } \\
\text { Nlrp3 }^{\mathrm{tm} 1 \mathrm{Vmd}}\end{array}$ & $\begin{array}{l}\text { Jackson } \\
\text { laboratories }\end{array}$ & RRID:MGI:5468973 & $\begin{array}{l}\text { In vivo } \\
\text { mouse } \\
\text { models } \\
\text { and } \\
\text { biological } \\
\text { samples. }\end{array}$ \\
\hline $\begin{array}{l}\text { Genetic } \\
\text { reagent } \\
\text { (Mus } \\
\text { musculus, } \\
\text { male) }\end{array}$ & $\begin{array}{l}\text { ASC- } \\
\text { deficient } \\
\text { mice } \\
\left(\text { Pycard }^{-1}\right) \\
\text { - C57 BL/6 } \\
\text { Pycard } \\
\text { md }\end{array}$ & $\begin{array}{l}\text { Jackson } \\
\text { laboratories }\end{array}$ & RRID:MGI:3047277 & $\begin{array}{l}\text { In vivo } \\
\text { mouse } \\
\text { models } \\
\text { and } \\
\text { biological } \\
\text { samples. }\end{array}$ \\
\hline $\begin{array}{l}\text { Genetic } \\
\text { reagent } \\
\text { (Mus } \\
\text { musculus, } \\
\text { male) }\end{array}$ & $\begin{array}{l}\text { Casp1/11- } \\
\text { deficient } \\
\text { mice } \\
\text { (Casp1/11 } \\
\text { ()- } \\
\text { B6N.129S } \\
2- \\
\text { Casp1 }^{\text {tm1Flv }}\end{array}$ & $\begin{array}{l}\text { Jackson } \\
\text { laboratories }\end{array}$ & RRID:MGI:5467384 & $\begin{array}{l}\text { Biologica } \\
\text { samples. }\end{array}$ \\
\hline Antibody & $\begin{array}{l}\text { Anti- } \\
\text { GSDMD } \\
\text { (rabbit } \\
\text { monoclona } \\
\text { I, clone } \\
\text { EPR19828 } \\
\text { ) }\end{array}$ & Abcam & $\begin{array}{l}\text { Cat\#: ab209845, } \\
\text { RRID:AB_2783550 }\end{array}$ & $\begin{array}{l}\text { WB } \\
(1: 2000)\end{array}$ \\
\hline Antibody & $\begin{array}{l}\text { Anti- } \\
\text { Caspase } 1 \\
\text { p20 (mose } \\
\text { monoclona } \\
\text { I, clone } \\
\text { Casper-1) }\end{array}$ & Adipogen & $\begin{array}{l}\text { casper-1, Cat\# AG- } \\
\text { 20B-0042, } \\
\text { RRID:AB_2490248 }\end{array}$ & $\begin{array}{l}\text { WB } \\
(1: 1000)\end{array}$ \\
\hline Antibody & $\begin{array}{l}\text { Anti-IL-1 } \\
\text { (rabbit } \\
\text { polyclonal) }\end{array}$ & Santa Cruz & $\begin{array}{l}\mathrm{H}-153 \\
\text { Cat\#: SC-7884, } \\
\text { RRID:AB_2124476 }\end{array}$ & $\begin{array}{l}\text { WB } \\
(1: 1000)\end{array}$ \\
\hline
\end{tabular}




\begin{tabular}{|c|c|c|c|c|}
\hline $\begin{array}{l}\text { Sequence } \\
\text {-based } \\
\text { reagent }\end{array}$ & $\begin{array}{l}\text { KiCqStart } \\
\text { SYBR } \\
\text { Green } \\
\text { Primers }\end{array}$ & Sigma-Aldrich & $\begin{array}{l}\text { Tnfa } \\
\text { (NM_013693) } \\
\text { Il6 } \\
\text { (NM_031168) } \\
\text { Il1b } \\
\text { (NM_008361) } \\
\text { Actb } \\
\text { (NM_007393) } \\
\text { Cox2 (Ptgs2) } \\
\text { (NM_011198) } \\
\text { Arg1 } \\
\text { (NM_007482) } \\
\text { Fizz1 (Retnlb) } \\
\text { (NM_023881) } \\
\text { Mrc1 } \\
\text { (NM_008625) } \\
\text { Ym1 (Chil1) } \\
\text { (NM_007695001080219 } \\
\text { ) }\end{array}$ & qRT-PCR \\
\hline $\begin{array}{l}\text { Commerci } \\
\text { al assay } \\
\text { or kit }\end{array}$ & $\begin{array}{l}\text { ELISA for } \\
\text { IL-1 } 1 \beta\end{array}$ & $\begin{array}{l}\text { R\&D } \\
\text { SystemsTher } \\
\text { mo Fisher } \\
\text { Scientific }\end{array}$ & $\begin{array}{l}\text { Cat\# 88-7013-88, } \\
\text { RRID:AB_257494688- } \\
\text { 7013-88xxx }\end{array}$ & $\begin{array}{l}\text { ELISA for } \\
\text { cell } \\
\text { supernata } \\
\text { nt }\end{array}$ \\
\hline $\begin{array}{l}\text { Commerci } \\
\text { al assay } \\
\text { or kit }\end{array}$ & $\begin{array}{l}\text { ELISA for } \\
\text { TNF } \alpha\end{array}$ & $\begin{array}{l}\text { Thermo } \\
\text { Fisher } \\
\text { Scientific }\end{array}$ & $\begin{array}{l}\text { Cat\# 88-7324-88, } \\
\text { RRID:AB_257508088- } \\
\text { 7324-88xxx }\end{array}$ & $\begin{array}{l}\text { ELISA for } \\
\text { cell } \\
\text { supernata } \\
\text { nt }\end{array}$ \\
\hline $\begin{array}{l}\text { Commerci } \\
\text { al assay } \\
\text { or kit }\end{array}$ & $\begin{array}{l}\text { ELISA for } \\
\text { IL-6 }\end{array}$ & $\begin{array}{l}\text { R\&D } \\
\text { Systems }\end{array}$ & $\begin{array}{l}\text { Cat\# M6000B, } \\
\text { RRID:AB_2877063 } \\
\text { M6000Bxxx }\end{array}$ & $\begin{array}{l}\text { ELISA for } \\
\text { cell } \\
\text { supernata } \\
\text { nt }\end{array}$ \\
\hline $\begin{array}{l}\text { Commerci } \\
\text { al assay } \\
\text { or kit }\end{array}$ & $\begin{array}{l}\text { ELISA for } \\
\text { IL-18 }\end{array}$ & $\begin{array}{l}\text { Thermo } \\
\text { Fisher } \\
\text { Scientific }\end{array}$ & $\begin{array}{l}\text { Cat\# BMS618/3, } \\
\text { RRID:AB_2575692BMS } \\
\text { 618-3xxx }\end{array}$ & $\begin{array}{l}\text { ELISA for } \\
\text { cell } \\
\text { supernata } \\
\text { nt }\end{array}$ \\
\hline $\begin{array}{l}\text { Chemical } \\
\text { compoun } \\
\text { d, drug }\end{array}$ & MCC950 & Sigma-Aldrich & PZ0280 & $\begin{array}{l}\text { Cell } \\
\text { culture: } \\
10 \mu \mathrm{M}\end{array}$ \\
\hline
\end{tabular}

383 Animals and percutaneous needle puncture procedure. All experimental protocols

384 for animal handling were refined and approved by the local animal research ethical

385 committee (references 241/2016 and 541/2019) and the Animal Health Service of the

386 General Directorate of Fishing and Farming of the Council of Murcia (Servicio de

387 Sanidad Animal, Dirección General de Ganadería y Pesca, Consejería de Agricultura y 
388 Agua de la Región de Murcia, reference A13160702). C57/BL6 mice (wild-type) were 389 obtained from Jackson Laboratories. NLRP3-deficient mice (N/rp3 $\left.{ }^{-/}\right)$and Caspase390 1/11-deficient mice (Casp-1/11 ${ }^{-/}$) in C57/BL6 background were a generous gift of I. 391 Coullin. For all experiments, mice between 8-10 weeks of age were used. Mice were bred in specific pathogen-free conditions with a 12:12 h light-dark cycle and used in accordance with the animal experimentation guidelines of the Hospital Clínico Universitario Vírgen de la Arrixaca, and the Spanish national (RD 1201/2005 and Law 32/2007) and EU (86/609/EEC and 2010/63/EU) legislation. Percutaneous needle puncture was performed with $16 \mathrm{G}$ and $13 \mathrm{~mm}$ needles (Agupunt) in the calcaneal tendon in isoflurane (Zoetis) anesthetized mice; galvanic current was applied using Physio Invasiva $\AA$ equipment (Prim) delivering three impacts of $3 \mathrm{~mA}$ for 3 seconds and compared to a puncture without current application. Paws without puncture were also used as controls. 3, 7, 14 and 21 days after puncture, animals were euthanized and paws were collected for histopathology or gene expression. Only calcaneal tendon was dissected for gene expression and the zone between gastrocnemius and calcaneus, including tendon, adipose tissue, tibia and peroneus, was dissected for histopathology.

Patient. A male patient, 36 years old with lateral epicondylalgia in the right elbow for 6 months, with pain and functional impairment. Resistant to conventional treatments

407 (physiotherapy, oral non-steroidal anti-inflammatory and local corticoid infiltrations).

408 Ultrasound analysis showed extensor joint tendon degeneration correlating with positive orthopedic tests. The patient was subjected to four sessions of percutaneous electrolysis with an intensity of $3 \mathrm{~mA}$ of galvanic current for $3 \mathrm{sec}, 3$ times (3:3:3), according to the protocol by Valera-Garrido and Minaya-Muñoz (Valera-Garrido and

412 Minaya-Muñoz, 2016).

414 Cell culture and treatments. Bone marrow-derived macrophages (BMDMs) were

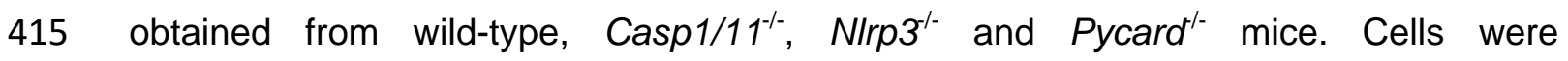


416 differentiated for 7 days in DMEM (Lonza) supplemented with 25\% L929 medium, 15\%

417 fetal bovine serum (FCS, Life Technologies), $100 \mathrm{U} / \mathrm{ml}$ penicillin/streptomycin (Lonza), 418 and $1 \%$ L-glutamine (Lonza). After differentiation, cells were primed for $2 \mathrm{~h}$ with $1 \mu \mathrm{g} / \mathrm{ml}$ 419 E. coli lipopolysaccharide (LPS) serotype O55:B5 at (Sigma-Aldrich) or for $4 \mathrm{~h}$ with 20 $420 \mathrm{ng} / \mathrm{ml}$ recombinant mouse IL-4 (BD Pharmigen). Cells were then washed twice with 421 isotonic buffer composed of $147 \mathrm{mM} \mathrm{NaCl}, 10 \mathrm{mM}$ HEPES, $13 \mathrm{mM}$ glucose, $2 \mathrm{mM}$ $422 \mathrm{CaCl}_{2}, 1 \mathrm{mM} \mathrm{MgCl}_{2}$, and $2 \mathrm{mM} \mathrm{KCl}, \mathrm{pH}$ 7.4, and then treated in OptiMEM (Lonza) with 423 different intensities and time of galvanic current (as indicated in the text and Figure 424 legends) using an ad hoc adaptor for 6 well plates (Figure 1-Figure supplement 1), 425 and then cultured for $6 \mathrm{~h}$. Alternatively and as a positive control, after LPS-priming 426 macrophages were treated for $6 \mathrm{~h}$ in OptiMEM with $1.5 \mu \mathrm{M}$ nigericin (Sigma-Aldrich) or

$4271 \mu \mathrm{g} / \mathrm{ml}$ Clostridium difficile toxin B (Enzo Life Sciences) to activate NLRP3 and Pyrin 428 inflammasomes respectively. In some experiments, cells were treated with $10 \mu \mathrm{M}$ of 429 the NLRP3 inflammasome inhibitor MCC950 (CP-456773, Sigma-Aldrich) after LPS 430 priming and during inflammasome activation.

431 Stable HEK293T cell lines constitutively expressing NLRP3-YFP have already been 432 produced (Tapia-Abellán et al., 2019). The cell line was not authenticated, but was routinely tested with the MycoProbe Mycoplasma Detection Kit following manufacturer 434 instructions (R\&D Systems) to ensure that it was free of mycoplasma. Cells were 435 subjected to two pulses of $12 \mathrm{~mA}$ of galvanic current during $6 \mathrm{~s}$ each and incubated for $436 \quad 6 \mathrm{~h}$ at $37^{\circ} \mathrm{C}$ and $5 \% \mathrm{CO}_{2}$ before being analyzed by fluorescence microscopy.

438 Fluorescence microcopy. Stable HEK293T cells were imaged with a Nikon Eclipse Ti 439 microscope equipped with a 20x S Plan Fluor objective (numerical aperture, 0.45), a 440 digital Sight DS-QiMc camera (Nikon), $472 \mathrm{~nm} / 520 \mathrm{~nm}, 543 \mathrm{~nm} / 593 \mathrm{~nm}$ filter sets 441 (Semrock), and the NIS-Elements AR software (Nikon). Images were analyzed with 442 ImageJ software (NIH). 
444 LDH release, Yo-Pro uptake assay and $\mathrm{K}^{+}$measurements. The presence of lactate

445 dehydrogenase (LDH) in cell culture supernatants was measured using the Cytotoxicity

446 Detection kit (Roche), following manufacturer's instructions. It was expressed as the

447 percentage of the total amount of LDH present in the cells. For Yo-Pro uptake, 448 macrophages were preincubated for 5 min at $37^{\circ} \mathrm{C}$ with $2.5 \mu \mathrm{M}$ of Yo-Pro- 1 iodide (Life

449 Technologies) after galvanic current application or 1\% triton X100 (Sigma-Aldrich)

450 application. Yo-Pro-1 fluorescence was measured after the treatments every 5 minutes

451 for the first $30 \mathrm{~min}$ and then every $30 \mathrm{~min}$ for the following $3 \mathrm{~h}$ with an excitation

452 wavelength of $478 \pm 20 \mathrm{~nm}$ and emission of $519 \pm 20 \mathrm{~nm}$ in a Synergy neo2 multi-mode

453 plate reader (BioTek). Intracellular $\mathrm{K}^{+}$was quantified using macrophages lysates, as

454 has already been reported (Compan et al., 2012), and measured by indirect

455 potentiometry on a Cobas 6000 with ISE module (Roche).

457 Western blot and ELISA. After cell stimulation, cells extracts were prepared in cold 458 lysis buffer and incubated at $4^{\circ} \mathrm{C}$ for $30 \mathrm{~min}$ and then centrifuged at $12856 \mathrm{xg}$ for 10 $459 \min$ at $4^{\circ} \mathrm{C}$. Cells supernatants were centrifuged at $12856 \mathrm{xg}$ for 30 seconds at $4^{\circ} \mathrm{C}$ and concentrated by centrifugation at $11000 \times g$ for 30 min at $4^{\circ} \mathrm{C}$ through a column with a 10 kDa cut-off (Merk-Millipore). Cell lysates and concentrated supernatants were mixed

462 with loading buffer (Sigma), boiled at $95^{\circ} \mathrm{C}$ for $5 \mathrm{~min}$, resolved in $15 \%$ polyacrylamide

463 gels and transferred to nitrocellulose membranes (BioRad). Different primary 464 antibodies were used for the detection of interest proteins: anti-IL-1 $\beta$ rabbit polyclonal 465 (1:1000, H-153, SC-7884, Santa Cruz), anti-caspase-1 (p20) mouse monoclonal 466 (1:1000, casper-1, AG-20B-0042, Adipogen), anti-gasdermin D rabbit monoclonal 467 (1:2000, EPR19828, ab209845, Abcam) and anti- $\beta$-Actin mouse monoclonal (1:10000, 468 Santa Cruz). Appropriate secondary antibody conjugated with HRP was used at 1:5000 469 dilution (Sigma) and developed with ECL plus (Amhershan Biosciences) in a 470 ChemiDoc HDR (BioRad). Uncropped Western blots are shown in Figure 2-source 471 data 1 and 2. The concentration of IL-1 $\beta$, IL-18, TNF- $\alpha$ and IL-6 in cell supernatants 
472 was determined by ELISA following the manufacturer's instructions. ELISA were 473 purchased from R\&D Systems or Thermo Fisher Scientific (see Key Resources Table).

474 Results were read in a Synergy Mx plate reader (BioTek).

475

476 Quantitative reverse transcriptase-polymerase chain reaction (RT-PCR) analysis.

477 Total RNA extraction was performed using macrophages or mice tendons dissected as 478 described above. Macrophage total RNA extraction was performed using the RNeasy 479 Mini Kit (Qiagen) following the manufacturer's instructions. Total RNA extraction from 480 mice tendons was performed using Qiazol lysis reagent (Qiagen) and samples were 481 homogenized using an Omni THQ homogenizer. After homogenization, samples were 482 incubated for $5 \mathrm{~min}$ at room temperature and centrifuged at $12000 \mathrm{xg}$ for $15 \mathrm{~min}$ at $4^{\circ} \mathrm{C}$. 483 After centrifugation, the upper phase was collected and one volume of $70 \%$ ethanol 484 was added. Samples were loaded in RNeasey Mini Kit columns and total RNA isolation 485 was performed following manufacturer's instructions. In both cases a step with a 486 treatment with $10 \mathrm{U} / \mu \mathrm{l}$ DNase I (Qiagen) was added during $30 \mathrm{~min}$. Reverse 487 transcription was performed using iScript cDNA Synthesis kit (BioRad). The mix SYBR 488 Green Premix ExTaq (Takara) was used for quantitative PCR in an iCyclerMyiQ 489 thermocycler (BioRad). Specific primers were purchased from Sigma (KiCqStart SYBR 490 Green Primers) for the detection of the different genes. Relative expression of genes 491 was normalized to the housekeeping gene Actb using the $2^{-\Delta \mathrm{Ct}}$ method and for the 492 expression in tendon then normalized to mean Ct value of non-treated samples using 493 the $2^{-\Delta \Delta C t}$ method (value shown in Figures). When expression in non-treated samples 494 was below threshold and was non detected (ND), $2^{-\Delta C t}$ values are shown in the Figures. 495 To compare gene expression between wild-type and knock-out mice, the fold change 496 of $2^{-\Delta \Delta C t}$ values of the knock-out mice was calculated with respect to the average of the $4972^{-\Delta \Delta C t}$ values of the wild-type mice. 
499 Histopathology. Mice paws were fixed using 4\% p-formaldehyde (Sigma-Aldrich) for

500 at least $24 \mathrm{~h}$, processed, paraffin-embedded, and sectioned in $4 \mu \mathrm{m}$ slides.

501 Hematoxylin and eosin stained slices were initially evaluated in a 0 to 3 qualitative

502 scale, with 0 being control (healthy tendon) conditions, 1 mild, 2 medium, and 3 severe,

503 for inflammatory infiltration and tendon cellularity grade (the median value for each of

504 the paws was used as the final value represented in the Figures). The number of

505 polymorphonuclear cells was quantified by counting 3 different fields for each sample,

506 and these cells were identified by their nuclear morphology. The number and area of

507 tenocytes nuclei was evaluated using the FIJI macro based on a manual threshold to

508 select nuclei and evaluating the different parameters measured with the "Analyze

509 particles" tool. Sirius red staining was performed in the slides using the Picro Sirius red

510 stain kit (Abcam) following the manufacturer's instructions and polarized light pictures

511 (Figure 7-Figure supplement 1D) were used to quantify the type of collagen by

512 converting pictures to SHG color and then using the CT-Fire algorithm to calculate

513 width, length, straightness and angle of collagen fibers in these pictures (Liu et al.,

514 2017). Toluidine blue staining was performed using a toluidine blue polychrome

515 solution (Bio-Optica) for metachromatic staining of acid substances, and this staining

516 was used for the mastocytes count. Immunohistochemistry with anti-F4/80 rat

517 monoclonal antibody (MCA497GA, BioRad) was used to quantify macrophages by

518 counting 3 different fields for each sample. All slides were examined with a Zeiss Axio

519 Scope AX10 microscope with 20x and 40x objectives (Carl Zeiss) and pictures were

520 taken with an AxioCam 506 Color (Carl Zeiss).

521

522 Biomechanical testing of tendons. Achilles tendons were dissected following the 523 protocol described in (Rigozzi et al., 2009). In brief, tendons were dissected 524 maintaining intact the calcaneus and the gastrocnemius/soleus muscles. The tendon

525 sheaths were also maintained in order to preserve the natural anatomical structure and

526 relative orientation of the individual tendon bundles (Figure 7-Figure supplement 
527 3A). Gastrocnemius/soleus muscle fibers were then cautiously removed to expose the

528 intramuscular tendon fibers (Figure 7-Figure supplement 3B). All mechanical tests

529 were performed with an Autograph AG-X plus 50N-5KN machine (Shimadzu) with a 530 speed of $0.1 \mathrm{~mm} / \mathrm{s}$ and $1 \mathrm{kN}$ load head. Specimens were clamped for testing with the 531 calcaneus mounted to approximate a neutral anatomical position (Figure 7-Figure supplement $3 \mathbf{C}$ ). Tendon area was calculated measuring tendon width in two

533 segments, frontal and lateral. Tendon area and length were then used to calculate

534 stiffness of tendons. Other parameters such as maximum force and maximum tension were also obtained. Elastic module was calculated as the slope of the curve generated representing force vs displacement. The slope was calculated taking into account the curve generated only between 1-2 $\mathrm{N}$ of force. All parameters were obtained using

538 Trapezium X software (Shimadzu).

540 Second harmonic generation microscopy. A detailed description of the second 541 harmonic generation microscope used can be found in (Skorsetz et al., 2016), a non542 lineal optical tool (Campagnola et al., 2001). Unstained collagen molecules are able to 543 generate second harmonic generation signal due to their natural structure with lack of a center of inversion symmetry (Fine and Hansen, 1971). The imaging instrument used

545 combines a Ti:Sapphire femtosecond laser source and an inverted microscope. The

546 laser system emits light pulses of $800 \mathrm{~nm}$ of wavelength at a repetition rate of $76 \mathrm{MHz}$.

547 An XY scanning unit and a Z-motor attached to the microscope objective allow the 548 sample to be scanned across the plane and depth location of interest. The second 549 harmonic generation signal from the sample propagates back through the same 550 objective used for excitation (dry long-working distance, $20 \mathrm{x}, 0.8 \mathrm{~N} . \mathrm{A}$.), is isolated by a 551 short-wave pass filter $(400 \pm 5 \mathrm{~nm})$, and finally detected by a photon counting 552 photomultiplier module. A home-made LabView ${ }^{\mathrm{TM}}$ software controlled the entire 553 system. The average power at the sample's plane was always below $100 \mathrm{~mW}$. Second 554 harmonic generation images were acquired at $2 \mathrm{~Hz}$. To analyze the structural 
555 organization of the collagen fibers in the tendon, an algorithm based on the Hough 556 transform was used (Bueno et al., 2020). The Hough transform is a mathematical 557 procedure able to detect aligned segments of collagen fibers (Figure 7-Figure 558 supplement 4) within an image, and provide quantitative information on the degree of 559 organization of the spatially resolved structures. On the basis of a pixel-by-pixel 560 calculation, when a straight line is found, the corresponding polar coordinates are filed 561 in the so-called 2D accumulator matrix. For each new detected straight line, the 562 accumulator increases one unit. The local peaks (i.e. maximum values) in this 563 accumulator space determine the preferential orientations found across the image. The 564 standard deviation of these orientations is defined as the structural dispersion. A 565 previously developed Matlab ${ }^{\mathrm{TM}}$ script was used for image processing (Bueno et al., 566 2020).

567

568 Statistics. Statistical analyses were performed using GraphPad Prism 7 (Graph-Pad 569 Software, Inc). A Shapiro-Wilk normality test was initially performed on all groups to 570 decide the analysis type to be used. For two-group comparisons, nonparametric Mann571 Whitney $U$ test (without making the assumption that values are normally distributed) or 572 the parametric unpaired $t$-test (for normal distributed data) were used to determine the 573 statistical significance. For more than two group comparisons, one-way ANOVA test 574 (for normal distributed data) or nonparametric Krustal-Wallis test (without making the 575 assumption that values are normally distributed) were used to determine the statistical 576 significance. Data are shown as mean values and error bars represent standard error 577 from the number of independent assays indicated in the figure legend, which are also 578 overlaid in the histograms as dot-plotting. $P$ value is indicated as ${ }^{*} p<0.05 ;{ }^{* *} p<0.01$; $579{ }^{* * *} p<0.001 ;{ }^{* * *} p<0.0001 ; p>0.05$ not significant $(n s)$. 
580 Acknowledgments We thank M.C. Baños (IMIB-Arrixaca, Murcia, Spain) for technical

581 assistance with molecular and cellular biology, A. García Martínez (CESMAR

582 Electromedicina) for electrode development for in vitro application of galvanic current,

583 D. Peñín Franch for helping in the development of the plugin to measure different types

584 of collagen, F.J. Ávila (University of Zaragoza, Spain) for sharing the Matlab ${ }^{\mathrm{TM}}$ script

585 that was used for image processing, A.J. Ortiz Ruiz (University of Murcia, Spain) for

586 helping with tendon mechanical measurements and F. Noguera and M. Martínez (IMIB-

587 Arrixaca, Murcia, Spain) for running the Hitachi ion detection system and the members

588 of P. Pelegrin's laboratory for comments and suggestions throughout this project. We

589 also want to acknowledge the support of the SPF-animal house from IMIB-Arrixaca.

590

591 Funding: A.P-F. was supported by MVClinic and Prim. This work was supported by

592 grants to P.P. from FEDER/Ministerio de Ciencia, Innovación y Universidades -

593 Agencia Estatal de Investigación (grant SAF2017-88276-R and PID2020-116709RB-

594 100), Fundación Séneca (grants 20859/PI/18 and 21081/PDC/19), and the European

595 Research Council (ERC-2013-CoG grant 614578 and ERC-2019-PoC grant 899636).

596 Ministerio de Ciencia e Innovación, Agencia Estatal de Investigación supported JMB

597 (grant PID2020-113919RB-I00).

598

\section{Declaration of interests}

600 F.Mi.-M. and F.V.-G. are employees of MVClinic Institute. A.P-F's contract was 601 supported by MVClinic Institute and Prim. P.P. declares that he is an inventor in a 602 patent filed on March 2020 by the Fundación para la Formación e Investigación 603 Sanitaria de la Región de Murcia (PCT/EP2020/056729) for a method to identify 604 NLRP3-immunocompromised sepsis patients. P.P. is consultant of Glenmark 605 Pharmaceutical and co-founder of Viva in vitro diagnostics SL. The remaining authors 606 declare no competing interests. 
607

608

609

610

611

612

613

614

615

616

617

618

619

620

621

622

623

624

625

626

627

628

629

630

631

632

633

634

\section{REFERENCES}

Abat F, Sánchez-Sánchez JL, Martín-Nogueras AM, Calvo-Arenillas JI, Yajeya J, Méndez-Sánchez R, Monllau JC, Gelber PE. 2016. Randomized controlled trial comparing the effectiveness of the ultrasound-guided galvanic electrolysis technique (USGET) versus conventional electro-physiotherapeutic treatment on patellar tendinopathy. J Exp Orthop 3:34. doi:10.1186/s40634-016-0070-4

Alegre F, Pelegrin P, Feldstein AE. 2017. Inflammasomes in Liver Fibrosis. Semin Liver Dis 37. doi:10.1055/s-0037-1601350

Amores-Iniesta J, Barberà-Cremades M, Martínez CMCM, Pons JAJA, Revilla-Nuin B, Martínez-Alarcón L, Di Virgilio F, Parrilla P, Baroja-Mazo A, Pelegrín P. 2017. Extracellular ATP Activates the NLRP3 Inflammasome and Is an Early Danger Signal of Skin Allograft Rejection. Cell Rep 21:3414-3426. doi:10.1016/j.celrep.2017.11.079

Baroja-Mazo A, Martín-Sánchez F, Gomez AI, Martínez CM, Amores-Iniesta J, Compan V, Barberà-Cremades M, Yagüe J, Ruiz-Ortiz E, Antón J, Buján S, Couillin I, Brough D, Arostegui JI, Pelegrín P, Martin-Sanchez F, Gomez Al, Martínez CM, Amores-Iniesta J, Compan V, Barberà-Cremades M, Yagüe J, RuizOrtiz E, Antón J, Buján S, Couillin I, Brough D, Aróstegui JI, Pelegrin P. 2014. The NLRP3 inflammasome is released as a particulate danger signal that amplifies the inflammatory response. Nat Immunol 15:738-748. doi:10.1038/ni.2919

Bisset L, Beller E, Jull G, Brooks P, Darnell R, Vicenzino B. 2006. Mobilisation with movement and exercise, corticosteroid injection, or wait and see for tennis elbow: randomised trial. BMJ 333:939. doi:10.1136/bmj.38961.584653.AE

Borthwick LA, Wynn TA, Fisher AJ. 2013. Cytokine mediated tissue fibrosis. Biochim Biophys Acta - Mol Basis Dis 1832:1049-1060. doi:10.1016/j.bbadis.2012.09.014

Boucher D, Monteleone M, Coll RC, Chen KW, Ross CM, Teo JL, Gomez GA, Holley CL, Bierschenk D, Stacey KJ, Yap AS, Bezbradica JS, Schroder K. 2018. Caspase-1 self-cleavage is an intrinsic mechanism to terminate inflammasome 
Broz P, Dixit VM. 2016. Inflammasomes: mechanism of assembly, regulation and signalling. Nat Rev Immunol 16:407-420. doi:10.1038/nri.2016.58

Broz P, Pelegrín P, Shao F. 2020. The gasdermins, a protein family executing cell death and inflammation. Nat Rev Immunol 20:143-157. doi:10.1038/s41577-0190228-2

Bubnov R. 2013. Ultrasound guided injections of Platelets Rich Plasma for muscle injury in professional athletes. Comparative study. Med Ultrason 15:101-105. doi:10.11152/mu.2013.2066.152.rb1vy2

Bueno JM, Ávila FJ, Hristu R, Stanciu SG, Eftimie L, Stanciu GA. 2020. Objective 645 analysis of collagen organization in thyroid nodule capsules using second harmonic generation microscopy images and the Hough transform. Appl Opt 59:6925-6931. doi:10.1364/AO.393721

649

650

Campagnola PJ, Clark HA, Mohler WA, Lewis A, Loew LM. 2001. Second-harmonic

Chellini F, Tani A, Zecchi-Orlandini S, Sassoli C. 2019. Influence of Platelet-Rich and Platelet-Poor Plasma on endogenous mechanisms of skeletal muscle repair/regeneration. Int J Mol Sci 20:683. doi:10.3390/ijms20030683

Chen J, Chen ZJ. 2018. Ptdlns4P on dispersed trans-Golgi network mediates NLRP3 655 inflammasome activation. Nature 564:71-76. doi:10.1038/s41586-018-0761-3

Cocco M, Pellegrini C, Martínez-Banaclocha H, Giorgis M, Marini E, Costale A, Miglio 657 G, Fornai M, Antonioli L, López-Castejón G, Tapia-Abellán A, Angosto D, HafnerBratkovič I, Regazzoni L, Blandizzi C, Pelegrín P, Bertinaria M. 2017. Development of an Acrylate Derivative Targeting the NLRP3 Inflammasome for the Treatment of Inflammatory Bowel Disease. J Med Chem 60:3656-3671.

662 Coll RC, Robertson AAB, Chae JJ, Higgins SC, Muñoz-Planillo R, Inserra MC, Vetter I, 

Núñez G, Latz E, Kastner DL, Mills KHG, Masters SL, Schroder K, Cooper MA, O'Neill LAJ. 2015. A small-molecule inhibitor of the NLRP3 inflammasome for the treatment of inflammatory diseases. Nat Med 21:248-255. doi:10.1038/nm.3806

667

668

669

670

671

672

673

674

675

676

677

678

679

680

681

682

683

684

685

686

687

688

689

690

Compan V, Baroja-Mazo A, López-Castejón G, Gomez Al, Martínez CM, Angosto D, Montero MT, Herranz AS, Bazán E, Reimers D, Mulero V, Pelegrín P. 2012. Cell Volume Regulation Modulates NLRP3 Inflammasome Activation. Immunity 37:487-500. doi:10.1016/j.immuni.2012.06.013

Cook JL, Purdam CR. 2009. Is tendon pathology a continuum? A pathology model to explain the clinical presentation of load-induced tendinopathy. Br J Sports Med 43:409-416. doi:10.1136/bjsm.2008.051193

Coombes BK, Bisset L, Brooks P, Khan A, Vicenzino B. 2013. Effect of corticosteroid injection, physiotherapy, or both on clinical outcomes in patients with unilateral lateral epicondylalgia: a randomized controlled trial. JAMA 309:461-9. doi:10.1001/jama.2013.129

Daniels MJD, Rivers-Auty J, Schilling T, Spencer NG, Watremez W, Fasolino V, Booth SJ, White CS, Baldwin AG, Freeman S, Wong R, Latta C, Yu S, Jackson J, Fischer N, Koziel V, Pillot T, Bagnall J, Allan SM, Paszek P, Galea J, Harte MK, Eder C, Lawrence CB, Brough D. 2016. Fenamate NSAIDs inhibit the NLRP3 inflammasome and protect against Alzheimer's disease in rodent models. Nat Commun 7. doi:10.1038/ncomms 12504

De-la-Cruz-Torres B, Barrera-García-Martín I, Valera-Garrido F, Minaya-Muñoz F, Romero-Morales C. 2020. Ultrasound-Guided Percutaneous Needle Electrolysis in Dancers with Chronic Soleus Injury: A Randomized Clinical Trial. EvidenceBased Complement Altern Med 2020:1-8. doi:10.1155/2020/4156258

Eming SA, Wynn TA, Martin P. 2017. Inflammation and metabolism in tissue repair and regeneration. Science (80- ) 356:1026-1030. doi:10.1126/science.aam7928 Evavold CL, Ruan J, Tan Y, Xia S, Wu H, Kagan JC. 2018. The pore-forming protein 
691

692

693

694

695

696

697

698

699

700

701

702

703

704

705

706

707

708

709

710

711

712

713

714

715

716

717

718

gasdermin D regulates interleukin-1 secretion from living macrophages. Immunity 48:35-44.e6. doi:10.1016/j.immuni.2017.11.013

Fine S, Hansen WP. 1971. Optical second harmonic generation in biological systems. Appl Opt 10:2350-3. doi:10.1364/AO.10.002350

García Vidal J, Pelegrín P, Escolar Reina P, Medina i Mirapeix F. 2019. Inflammatory response of two invasive techniques in the mouse with collagenase induced tendinopathy. Rev Fisioter Invasiva / J Invasive Tech Phys Ther 02:080-080. doi:10.1055/s-0039-3401862

Gaul S, Leszczynska A, Alegre F, Kaufmann B, Johnson CD, Adams LA, Wree A, Damm G, Seehofer D, Calvente CJ, Povero D, Kisseleva T, Eguchi A, McGeough MD, Hoffman HM, Pelegrin P, Laufs U, Feldstein AE. 2020. Hepatocyte pyroptosis and release of inflammasome particles induce stellate cell activation and liver fibrosis. J Hepato/ S0168-8278:30522-30525. doi:10.1016/j.jhep.2020.07.041

Heneka MT, Kummer MP, Stutz A, Delekate A, Schwartz S, Vieira-Saecker A, Griep A, Axt D, Remus A, Tzeng T, Gelpi E, Halle A, Korte M, Latz E, Golenbock DT. 2013. NLRP3 is activated in Alzheimer's disease and contributes to pathology in APP/PS1 mice. Nature 493:674-678. doi:10.1038/nature11729

Krupenevich RL, Beck ON, Sawicki GS, Franz JR. 2021. Reduced Achilles Tendon Stiffness Disrupts Calf Muscle Neuromechanics in Elderly Gait. Gerontology 1-11. doi:10.1159/000516910

Li Y, Fu T-M, Lu A, Witt K, Ruan J, Shen C, Wu H. 2018. Cryo-EM structures of ASC and NLRC4 CARD filaments reveal a unified mechanism of nucleation and activation of caspase-1. Proc Natl Acad Sci U S A 115:10845-10852. doi:10.1073/pnas. 1810524115

Liston A, Masters SL. 2017. Homeostasis-altering molecular processes as mechanisms of inflammasome activation. Nat Rev Immunol 17:208-214. doi:10.1038/nri.2016.151

Liu Y, Keikhosravi A, Mehta GS, Drifka CR, Eliceiri KW. 2017. Methods for Quantifying 
Margalef R, Bosque M, Monclús P, Flores P, Minaya-Muñoz F, Valera-Garrido F, Santafé MM. 2020. Percutaneous Application of Galvanic Current in Rodents Reverses Signs of Myofascial Trigger Points. Evidence-Based Complement Altern Med 2020:1-9. doi:10.1155/2020/4173218

Margalef R, Minaya Muñoz F, Valera Garrido F, Santafe M. 2019. Vasodilation secondary to exposure to galvanic currents. Rev Fisioter Invasiva / J Invasive Tech Phys Ther 02:107-107. doi:10.1055/s-0039-3401880

Martínez-García JJ, Martínez-Banaclocha H, Angosto-Bazarra D, de Torre-Minguela C, Baroja-Mazo A, Alarcón-Vila C, Martínez-Alarcón L, Amores-Iniesta J, MartínSánchez F, Ercole GAGA, Martínez CMCM, González-Lisorge A, FernándezPacheco J, Martínez-Gil P, Adriouch S, Koch-Nolte F, Luján J, Acosta-Villegas F,

Masters SL, Dunne A, Subramanian SL, Hull RL, Tannahill GM, Sharp FA, Becker C, Franchi L, Yoshihara E, Chen Z, Mullooly N, Mielke LA, Harris J, Coll RC, Mills

Mayor A, Tardivel A, Martinon F, Pe V, Pétrilli V, Mayor A, Tardivel A, Tschopp J. 2006. Gout-associated uric acid crystals activate the NALP3 inflammasome. Nature 440:237-241. doi:10.1038/nature04516 O\&apos;Neill LAJ. 2010. Activation of the NLRP3 inflammasome by islet amyloid polypeptide provides a mechanism for enhanced IL-1 $\beta$ in type 2 diabetes. Nat Immunol 11:897-904. doi:10.1038/ni.1935

Medina i Mirapeix F, García Vidal J, Escolar Reina P, Martínez Cáceres C. 2019. Histopathological analysis of the inflammatory response of two invasive techniques in the calcaneal tendon of a mouse. Rev Fisioter Invasiva / J Invasive Tech Phys Ther 02:091-091. doi:10.1055/s-0039-3401870 
Medzhitov R. 2008. Origin and physiological roles of inflammation. Nature 454:428-35. doi:10.1038/nature07201

749

750

751

752

753

754

755

756

757

758

759

760

761

762

763

764

765

766

767

768

769

770

771

772

773

774

Moreno C, Mattiussi G, Núñez FJ, Messina G, Rejc E. 2017. Intratissue percutaneous electolysis combined with active physical therapy for the treatment of adductor longus enthesopathy-related groin pain: a randomized trial. J Sports Med Phys Fitness 57. doi:10.23736/S0022-4707.16.06466-5

Muñoz-Planillo R, Kuffa P, Martínez-Colón G, Smith BL, Rajendiran TM, Nunez G, Núñez G, Munoz-Planillo R, Kuffa P, Martinez-Colon G, Smith BL, Rajendiran TM, Nunez G. 2013. K+ Efflux Is the Common Trigger of NLRP3 Inflammasome Activation by Bacterial Toxins and Particulate Matter. Immunity 38:1142-1153. doi:10.1016/j.immuni.2013.05.016S1074-7613(13)00243-4 [pii]

Oreff GL, Fenu M, Vogl C, Ribitsch I, Jenner F. 2021. Species variations in tenocytes' response to inflammation require careful selection of animal models for tendon research. Sci Rep 11:12451. doi:10.1038/s41598-021-91914-9

Petrilli V, Papin S, Dostert C, Mayor A, Martinon F, Tschopp J. 2007. Activation of the NALP3 inflammasome is triggered by low intracellular potassium concentration. Cell Death Differ 14:1583-1589. doi:10.1038/sj.cdd.4402195

Próchnicki T, Mangan MS, Latz E. 2016. Recent insights into the molecular mechanisms of the NLRP3 inflammasome activation. F1000Research 5:14151469. doi:10.12688/f1000research.8614.1

Regan W, Wold LE, Coonrad R, Morrey BF. 1992. Microscopic histopathology of chronic refractory lateral epicondylitis. Am J Sports Med 20:746-749. doi:10.1177/036354659202000618

Rigozzi S, Müller R, Snedeker JG. 2009. Local strain measurement reveals a varied regional dependence of tensile tendon mechanics on glycosaminoglycan content. J Biomech 42:1547-1552. doi:10.1016/j.jbiomech.2009.03.031

Rodríguez-Huguet M, Góngora-Rodríguez J, Rodríguez-Huguet P, Ibañez-Vera AJ, Rodríguez-Almagro D, Martín-Valero R, Díaz-Fernández Á, Lomas-Vega R. 2020. 
Effectiveness of Percutaneous Electrolysis in Supraspinatus Tendinopathy: A Single-Blinded Randomized Controlled Trial. J Clin Med 9:1837. doi:10.3390/jcm9061837

778

779

780

781

782

783

784

785

786

787

788

789

790

791

792

793

794

795

796

797

798

799

800

801

802

Rühl S, Shkarina K, Demarco B, Heilig R, Santos JC, Broz P. 2018. ESCRT-dependent membrane repair negatively regulates pyroptosis downstream of GSDMD activation. Science 362:956-960. doi:10.1126/science.aar7607

Schmidt FI, Lu A, Chen JW, Ruan J, Tang C, Wu H, Ploegh HL. 2016. A single domain antibody fragment that recognizes the adaptor ASC defines the role of ASC domains in inflammasome assembly. J Exp Med 213:771-90. doi:10.1084/jem.20151790

Schroder K, Tschopp J, Couillin I, Pétrilli V, Martinon F, Schroder K, Tschopp J, Couillin I, Petrilli V, Martinon F. 2011. The Inflammasomes. Cell 140:821-832. doi:10.1016/j.cell.2010.01.040

Shook BA, Wasko RR, Rivera-Gonzalez GC, Salazar-Gatzimas E, López-Giráldez F, Dash BC, Muñoz-Rojas AR, Aultman KD, Zwick RK, Lei V, Arbiser JL, MillerJensen K, Clark DA, Hsia HC, Horsley V. 2018. Myofibroblast proliferation and heterogeneity are supported by macrophages during skin repair. Science (80- ) 362:eaar2971. doi:10.1126/science.aar2971

Skorsetz M, Artal P, Bueno JM. 2016. Performance evaluation of a sensorless adaptive optics multiphoton microscope. J Microsc 261:249-58. doi:10.1111/jmi.12325

Soslowsky LJ, Thomopoulos S, Tun S, Flanagan CL, Keefer CC, Mastaw J, Carpenter JE. 2000. Neer Award 1999. Overuse activity injures the supraspinatus tendon in an animal model: a histologic and biomechanical study. J shoulder Elb Surg 9:79_ 84.

Taabazuing CY, Okondo MC, Bachovchin DA. 2017. Pyroptosis and Apoptosis Pathways Engage in Bidirectional Crosstalk in Monocytes and Macrophages. Cell Chem Biol 24:507-514.e4. doi:10.1016/j.chembiol.2017.03.009

Tapia-Abellán A, Angosto-Bazarra D, Alarcón-Vila C, Baños MC, Hafner-Bratkovič I, 

in a stable open structure that promotes inflammasome activation. Sci Adv 7. doi:10.1126/sciadv.abf4468

806

807

808

809

810

811

812

813

814

815

816

817

818

819

820

821

822

823

824

825

826

827

828

829

830

Tapia-Abellán A, Angosto-Bazarra D, Martínez-Banaclocha H, de Torre-Minguela C, Cerón-Carrasco JPJP, Pérez-Sánchez H, Arostegui JIJIJIJI, Pelegrin P. 2019. MCC950 closes the active conformation of NLRP3 to an inactive state. Nat Chem Biol 15:560-564. doi:10.1038/s41589-019-0278-6

Valera-Garrido F, Jiménez-Rubio S, Minaya-Muñoz F, Estévez-Rodríguez JL, Navandar A. 2020. Ultrasound-Guided Percutaneous Needle Electrolysis and Rehab and Reconditioning Program for Rectus Femoris Muscle Injuries: A Cohort Study with Professional Soccer Players and a 20-Week Follow-Up. App/ Sci 10:7912. doi:10.3390/app10217912

Valera-Garrido F, Minaya-Muñoz F. 2019. Fundamentos y principios de la electrolisis percutánea musculoesquelética In: Valera-Garrido F, Minaya-Muñoz F, editors. Fisioterapia Invasiva. Barcelona: Elsevier. pp. 390-391.

Valera-Garrido F, Minaya-Muñoz F. 2016. Aplicaciones clínicas de la electrolisis percutánea In: Valera-Garrido F, Minaya-Muñoz F, editors. Fisioterapia Invasiva. Barcelona: Elsevier. p. 425.

Valera-Garrido F, Minaya-Muñoz F, Medina-Mirapeix F. 2014. Ultrasound-Guided Percutaneous Needle Electrolysis in Chronic Lateral Epicondylitis: Short-Term and Long-Term Results. Acupunct Med 32:446-454. doi:10.1136/acupmed-2014010619

Valera-Garrido F, Minaya-Muñoz F, Sánchez-Ibáñez JM, García-Palencia P, Valderrama-Canales F, Medina-Mirapeix F, Polidori F. 2013. Comparison of the acute inflammatory response and proliferation of dry needling and electrolysis percutaneous intratissue (EPI) in healthy rat achilles tendons. $\mathrm{Br} J$ Sports Med 47:e2.52-e2. doi:10.1136/bjsports-2013-092459.56

Wynn T. 2008. Cellular and molecular mechanisms of fibrosis. J Pathol 214:199-210. 
831 doi:10.1002/path.2277

832 
Figure 1. Galvanic current increases the M1 phenotype of macrophages.

836

(A) Quantitative PCR for M1 genes Cox2, I/6, I/1b and Tnfa expression from mouse bone marrow derived macrophages (BMDMs) treated for $2 \mathrm{~h}$ with LPS $(1 \mu \mathrm{g} / \mathrm{ml})$ or $4 \mathrm{~h}$ with IL-4 $(20 \mathrm{ng} / \mathrm{\mu l})$ as indicated and then 2 impacts of $12 \mathrm{~mA}$ of galvanic current for 6 seconds. Cells were then further cultured for $6 \mathrm{~h}$ before analysis. Center values represent the mean and error bars represent s.e.m.; $n=5-10$ samples of 5 independent experiments; for Cox2 unpaired $t$-test except in the two first columns where MannWhitney tests were performed, for $1 / 6$ Mann-Whitney test except in LPS vs LPS+galvanic current comparison where unpaired $t$-tests were performed, for $/ 11 \mathrm{~b}$ Mann-Whitney test, for Tnfa unpaired $t$-test except in LPS vs LPS+galvanic current comparison where Mann-Whitney were performed, ${ }^{* * *} p<0.0005,{ }^{* *} p<0.005,{ }^{*} p<0.05$, and $n s p>0.05$.

847 (B) Quantitative PCR for M2 genes Arg1, Fizz1, Mrc1 and Ym1 expression from

848 BMDMs treated as in (A). Center values represent the mean and error bars represent s.e.m.; $n=3-10$ samples of 5 independent experiments; unpaired $t$-test except LPS $v S$ LPS+galvanic current comparison where Mann-Whitney tests were performed, ${ }^{* * *} p<0.0005,{ }^{*} p<0.05$, and $n s p>0.05$.

852 (C) IL-6, TNF- $\alpha$ and IL-1 $\beta$ release from BMDMs treated as in (A) but with different intensities of galvanic current $(3,6,12 \mathrm{~mA})$. Center values represent the mean and error bars represent s.e.m.; $n=2$ for untreated cells and $n=4-6$ for treatment groups from 4 independent experiments; one-way ANOVA were performed comparing treated groups with the control group, ${ }^{* * *} p<0.0001,{ }^{*} p<0.05$, and $n s p>0.05$. 
861 inflammasome.

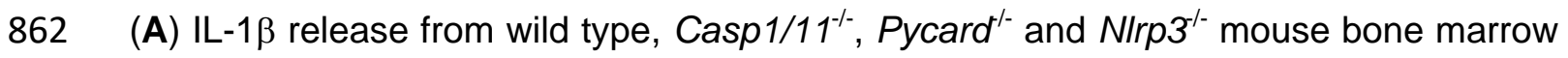
863 derived macrophages (BMDMs) treated for $2 \mathrm{~h}$ with LPS $(1 \mu \mathrm{g} / \mathrm{ml})$ and then 2 impacts 864 of different intensities of galvanic current $(3,6,12 \mathrm{~mA})$ for 6 seconds. Cells were then 865 further cultured for $6 \mathrm{~h}$ before cytokine were measured in supernatant. Center values 866 represent the mean and error bars represent s.e.m.; $n=6-16$ samples of 10 867 independent experiments; LPS vs LPS+galvanic current in wild-type and wild-type vs 868

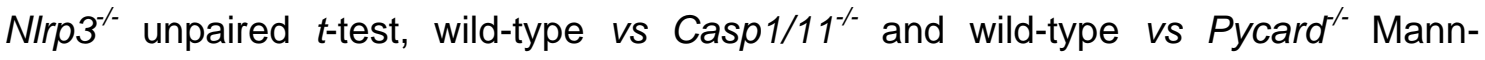
869 Whitney test, ${ }^{* *} p<0.005$.

870 (B) IL-1 $\beta$ release from wild type BMDMs treated as in A but applying the NLRP3 specific inhibitor MCC950 $(10 \mu \mathrm{M}) 30$ min before the galvanic current application and during the last $6 \mathrm{~h}$ of culture. As a control, cells were treated with nigericin $(1,5 \mu \mathrm{M})$ rather than galvanic current. Center values represent the mean and error bars represent s.e.m.; $n=5-10$ samples of 5 independent experiments; nigericin $v s$ nigericin+MCC950 Mann-Whitney test, galvanic current vs galvanic current+MCC950 unpaired t-test, ${ }^{* * * *} p<0.0001$ and ${ }^{* * *} p<0.0005$. (C) IL-18 release from BMDMs treated as in A. Center values represent the mean and error bars represent s.e.m.; $n=2-7$ samples of at least 2 independent experiments. (D) IL-1 $\beta$ release from wild type BMDMs treated as in A but applying a buffer with 40 $\mathrm{mM}$ of $\mathrm{KCl}$ (high $\mathrm{K}^{+}$buffer) during the last $6 \mathrm{~h}$ of culture. As controls, cells were treated with nigericin $(1,5 \mu \mathrm{M})$ or Clostridium difficile toxin $\mathrm{B}(1 \mu \mathrm{g} / \mathrm{ml})$ rather than galvanic current. Center values represent the mean and error bars represent s.e.m.; $n=3-12$ samples of 4 independent experiments; unpaired $t$-test, ${ }^{* * * *} p<0.0001,{ }^{* *} p<0.005$ and $n s p>0.05$.

885 (E) Intracellular $\mathrm{K}^{+}$concentration from wild type BMDMs primed with LPS as in A, but 886 then treated for $6 \mathrm{~h}$ with nigericin $(1.5 \mu \mathrm{M})$ or 2 or 8 impacts of $12 \mathrm{~mA}$ for 6 or $12 \mathrm{sec}$ as 
887 indicated. Center values represent the mean and error bars represent s.e.m.; $n=3-8$

888 samples of 3 independent experiments; Mann-Whitney test, ${ }^{* *} p<0.005$ and ${ }^{*} p>0.05$.

889 (F) Immunoblot of cell extract and supernatants for caspase-1, IL-1 $\beta$, GSDMD and $\beta$ 890 actin from wild type BMDMs treated as in B, but with 8 impacts. Representative of $n=2$ 891 independent experiments.

892 (G) Fluorescence microscopy of HEK293T cells stably expressing NLRP3-YFP after 6

$893 \mathrm{~h}$ of application of 2 impacts of $12 \mathrm{~mA}$ of galvanic current for 6 seconds, the specific 894 inhibitor MCC950 (10 $\mu \mathrm{M})$ was added 30 min before the galvanic current; scale bar 10 895 $\mu \mathrm{m} ; n=3$ independent experiments.

896

897

Figure 3. Galvanic current does not induce inflammasome-mediated pyroptosis.

898 (A) Extracellular amount of LDH determining cell membrane damage from mouse bone 899 marrow derived macrophages (BMDMs) treated for $2 \mathrm{~h}$ with LPS $(1 \mu \mathrm{g} / \mathrm{ml})$ and then 2 900 or 8 impacts of different intensities of galvanic current $(3,6,12 \mathrm{~mA})$ for 6 or 12 seconds 901 were applied as indicated. Cells were then further cultured for $6 \mathrm{~h}$ before LDH 902 determination in supernatant. Center values represent the mean and error bars 903 represent s.e.m.; $n=3-4$ samples of 6 independent experiments; Kruskal-Wallis test to 904 compare LPS with increasing intensities of galvanic current, LPS vs LPS+ galvanic 905 current (12mA-12s)x2 unpaired $t$-test, LPS vs LPS+ galvanic current (12mA-6s)x8, 906 ${ }^{* * *} p<0.0001,{ }^{* * *} p<0.0005$ and ${ }^{*} p<0.05$.

907 (B) Extracellular amount of LDH from wild type, NIrp3 ${ }^{-/}$, Pycard ${ }^{1-}$ and Casp1/11 ${ }^{-1-}$ 908 mouse BMDMs treated as in A. Center values represent the mean and error bars 909 represent s.e.m.; $n=6-17$ samples of 12 independent experiments; unpaired $t$-test except for Casp $1 / 11^{-/}$comparison, ${ }^{* *} p<0.0005$ and ${ }^{*} p<0.05$.

911 (C) IL-1 $\beta$ (left) and IL-18 (right) release from wild type BMDMs treated as in A, but applying the NLRP3 specific inhibitor MCC950 $(10 \mu \mathrm{M})$ during the last $6 \mathrm{~h}$ of culture. 
913 Center values represent the mean and error bars represent s.e.m.; $n=6-10$ samples of

9145 independent experiments; unpaired $t$-test, ${ }^{* * *} p<0.0001$ and ${ }^{*} p<0.005$.

915 (D) Extracellular amount of LDH from wild type BMDMs treated as in C. Center values 916 represent the mean and error bars represent s.e.m.; $n=5-10$ samples of 5 independent 917 experiments; unpaired $t$-test, $n s p>0.005$.

918 (E) Kinetic of Yo-Pro-1 uptake (upper panel) or slope of the uptake (lower panel) in wild

919 type BMDMs treated for $2 \mathrm{~h}$ with LPS $(1 \mu \mathrm{g} / \mathrm{ml})$ and then with different intensities of 920 galvanic current (as indicated) or with the detergent triton X-100 (1\%) for $3.5 \mathrm{~h}$. Center 921 values represent the mean and error bars represent s.e.m.; $n=3-6$ of 3 independent 922 experiments; Kruskal-Wallis test, ${ }^{* *} p<0.0005,{ }^{* *} p<0.005$ and $n s p>0.05$.

923 (F) Yo-Pro-1 uptake indicating plasma membrane pore formation and cell viability. 924 Kinetic of Yo-Pro-1 uptake (upper panel) or slope of the uptake (lower panel) in wild 925 type or Pycard ${ }^{1-}$ BMDMs treated as in E but, when indicated, the NLRP3 specific 926 inhibitor MCC950 (10 $\mu \mathrm{M})$ was added after galvanic current application. Center values represent the mean and error bars represent s.e.m.; $n=3-6$ samples of 3 independent 928 experiments; unpaired $t$-test, ${ }^{* *} p<0.005,{ }^{*} p<0.05$ and $n s p>0.05$.

929

930 Figure 4. Galvanic current induces polymorphonuclear and macrophage infiltrate 931 in the calcaneal tendon of mice.

932 (A) Representative hematoxylin and eosin images of wild type mice calcaneal tendon after 3 days' application of 3 punctures with needle (needling, green) or 3 impacts of 3 $\mathrm{mA}$ for $3 \mathrm{sec}$ (blue). Scale bar: $50 \mu \mathrm{m}$. Magnification show the presence of polymorphonuclear cells (arrowheads).

936 (B) Quantification of polymorphonuclear cells per field of view of calcaneal tendon

937 sections treated and stained as described in A. Center values represent the mean and 938 error bars represent s.e.m.; $n=7-8$ independent animals; unpaired $t$-test, ${ }^{*} p<0.005$. 
939 (C) Representative immunostaining images for the macrophage marker F4/80 from the

940 calcaneal tendon of wild type mice treated as described in A. Scale bar: $50 \mu \mathrm{m}$.

941 Magnification show the presence of F4/80 positive cells (arrowheads).

942 (D) Quantification of F4/80 positive cells per field of view of calcaneal tendon sections 943 treated and stained as described in C. Center values represent the mean and error 944 bars represent s.e.m.; $n=8$ independent animals; Mann-Whitney test, ${ }^{*} p<0.005$.

945

946 Figure 5. Galvanic current induces proinflammatory cytokine expression in the 947 calcaneal tendon of mice.

948 (A,B) Quantitative PCR for the indicated genes normalized to Actb in the calcaneal 949 tendon of wild type mice after 3 days of applying 3 punctures with needle (needling, 950 green) or 3 impacts of $3 \mathrm{~mA}$ for $3 \mathrm{sec}$ (blue), and compared to the expression of genes 951 in non-treated tendons. Center values represent the mean and error bars represent 952 s.e.m.; $n=4-12$ independent animals; for II6, NIrp3, Pycard and Gsdmd unpaired $t$-test, 953 for I/1b untreated vs galvanic current Mann-Whitney and puncture vs galvanic current 954 unpaired $t$-test, for $C x c / 10$, I/1rn and Casp1/11 Mann-Whitney test, for I/1a one sample 955 Wilcoxon test (ND: non detected), ${ }^{* *} p<0.0005,{ }^{* *} p<0.005,{ }^{*} p<0.05$ and $n s p>0.05$.

956

957 Figure 6. Inflammatory response in the calcaneal tendon of $\mathrm{NIrp3}^{/-}$mice after 958 galvanic current application.

959 (A-C) Quantitative PCR for the indicated genes in the calcaneal tendons of N/rp3 ${ }^{-/}$ 960 mice (calculated as $2^{-\Delta \Delta \mathrm{Ct}}$ ) normalized to the expression in wild type (calculated as $2^{-}$ $961^{\Delta \Delta \mathrm{Ct}}$ ) after 3 days of 3 impacts of $3 \mathrm{~mA}$ for $3 \mathrm{sec}$. Center values represent the mean and 962 error bars represent s.e.m.; $n=3-12$ independent animals; for $/ 11 b$, NIrp3, Pycard, 963 Casp1/11 and Gsdmd unpaired $t$-test, for $/ / 1 r n$ and $C x c / 10$ Mann-whitney test, ${ }^{*} p<0.05$ 964 and $n s p>0.05$. 
(D) Quantification of polymorphonuclear (top) and F4/80 positive cells (bottom) per field of view from wild type and $\mathrm{N}_{\mathrm{r} p 3^{-/}}$mice calcaneal tendon treated as in A. Center values represent the mean and error bars represent s.e.m.; $n=6-8$ independent animals; unpaired $t$-test, ${ }^{*} p<0.05$ and $n s p>0.05$. Representative hematoxylin and eosin images (top) and F4/80 immunostaining (bottom) of calcaneal tendon quantified. Scale bar: 50 $\mu \mathrm{m}$. Magnification shows the presence of polymorphonuclear (top) or F4/80 cells (bottom) denoted by arrowheads.

972

Figure 7. Galvanic current increase in type I collagen via NLRP3 inflammasome.

974 (A) Quantitative PCR for Tgfb1 in the calcaneal tendons of N/rp3 ${ }^{-/}$mice (calculated as $2^{-\Delta \Delta \mathrm{Ct}}$ ) normalized to the expression in wild type (calculated as $2^{-\Delta \Delta \mathrm{Ct}}$ ) after 3 days of 3 impacts of $3 \mathrm{~mA}$ for $3 \mathrm{sec}$. Center values represent the mean and error bars represent s.e.m.; $n=6-12$ independent animals; Mann-Whitney test, ${ }^{* * *} p<0.0005$. (B,C) Quantification of the collagen type I and III in calcaneal tendon sections stained with picrosirius red from wild type $(\mathrm{B}, \mathrm{C})$ and $\mathrm{NIrp3}^{-/}(\mathrm{C})$ mice after 3,7 or 14 days $(\mathrm{B})$ or 3 days $(C)$ application of punctures with needle (needling, green) or 3 impacts of $3 \mathrm{~mA}$ for $3 \mathrm{sec}$ (blue), or in non-treated tendons (white). Center values represent the mean and error bars represent s.e.m.; $n=3-12$ independent animals; for 3 days and panel $C$ unpaired $t$-test, for 7 days non-treated vs needling Mann-Whitney test and non-treated vs percutaneous electrolysis unpaired $t$-test, for 14 days untreated vs needling unpaired $t$-test and untreated vs percutaneous electrolysis Mann-Whitney test, ${ }^{* *} p<0.005,{ }^{*} p<0.05$ and $n s p>0.05$.

(D) Quantification of collagen structural dispersion in calcaneal tendon sections imaged with second harmonic generation microscopy and calculated with an algorithm based on the Hough transform from wild type and $\mathrm{NIrp3}^{-/-}$mice after 7 days of 3 impacts of 3 $\mathrm{mA}$ for $3 \mathrm{sec}$ (blue), or in non-treated tendons (white). Center values represent the mean and error bars represent s.e.m.; $n=3$ independent animals imaged at 2 or 3 different tendon areas, one-way ANOVA ${ }^{* * *} p<0.0005$ and ${ }^{*} p<0.05$. 
993 (E) Biomechanical testing of calcaneal tendon from wild-type and N/rp3 ${ }^{-/}$mice after 14 994 days of 3 impacts of $3 \mathrm{~mA}$ for $3 \mathrm{sec}$ (blue) or from non-treated tendons (white). Center 995 values represent the mean and error bars represent s.e.m.; $n=3-8$ independent 996 animals; unpaired $t$-test, ${ }^{*} p<0.05$ and $n s p>0.05$.

997 
Figure 1-Figure supplement 1 . Device designed to apply galvanic current in 61001 well plates.

1002

The two poles are separated by plastic spacers and generate a homogeneous and constant galvanic current throughout the well.

1004

1005

1006

Figure 2-Figure supplement 1. Galvanic current does not induce a detectable decrease in intracellular $\mathrm{K}^{+}$.

1007

(A) IL-1 $\beta$ release from wild type, Casp $1 / 11^{-/-}$, Pycard $^{/-}$and $\mathrm{NIrp3}^{/-}$mouse bone marrow 1008 derived macrophages (BMDMs) treated for $2 \mathrm{~h}$ with LPS $(1 \mu \mathrm{g} / \mathrm{ml})$ and then with $6 \mathrm{~h}$

1009 with nigericin $(1 \mu \mathrm{M})$. Center values represent the mean and error bars represent

1010 s.e.m.; $n=2-8$ samples of 3 independent experiments; unpaired $t$-test, ${ }^{* *} p<0.005$.

1011

(B) Intracellular $\mathrm{K}^{+}$concentration from wild type BMDMs primed with LPS as in A, but

1012 then treated for 30 min with nigericin $(1 \mu \mathrm{M})$ or for the indicated time after 2 impacts of $12 \mathrm{~mA}$ for $6 \mathrm{sec}$. Center values represent the mean and error bars represent s.e.m.; $n=$ 5-9 samples of 9 independent experiments; LPS vs LPS+nigericin unpaired $t$-test and LPS vs LPS+galvanic current at different times one-way ANOVA, ${ }^{* \star *} p<0.0005$ and $n s$ $1016 p>0.05$.

1017

1018 Figure 4-Figure supplement 1. Galvanic current does not affect tendon 1019 mastocytes, tenocytes or vascularity.

1020

(A) Quantification of mastocytes per field of view of calcaneal tendon sections stained with toluidine blue from wild type mice after 3 days application of 3 punctures with needle (needling, green) or 3 impacts of $3 \mathrm{~mA}$ for $3 \mathrm{sec}$ (blue). Center values represent

1023 the mean and error bars represent s.e.m.; $n=6-15$ independent animals; Mann- 
1024 Whitney test, ${ }^{*} p<0.05$. Images on the right show representative sections where 1025 mastocytes were counted, scale bar $50 \mu \mathrm{m}$.

1026 (B) IL-1 $\beta$ and LDH release from mice bone-marrow isolated neutrophils primed for $2 \mathrm{~h}$

1027 with LPS $(1 \mu \mathrm{g} / \mathrm{ml})$ and then treated for $30 \mathrm{~min}$ with ATP $(3 \mathrm{mM})$ or $6 \mathrm{~h}$ after application 1028 of 2 impacts of $12 \mathrm{~mA}$ of galvanic current for 6 seconds. Center values represent the 1029 mean and error bars represent s.e.m.; $n=3$ independent animals.

1030 (C) Representative hematoxylin and eosin images of wild type mice calcaneal tendon 1031 untreated or after 3 days of 3 punctures with needle (needling) or 3 impacts of $3 \mathrm{~mA}$ for $10323 \mathrm{sec}$ (percutaneous electrolysis), scale bar $200 \mu \mathrm{m}$.

1033 (D,E,F) Number, area and circularity of nuclei of tenocytes of calcaneal tendon sections of wild type mice stained with hematoxylin and eosin after 3 days of 3 1035 punctures with needle (needling, green) or 3 impacts of $3 \mathrm{~mA}$ for $3 \mathrm{sec}$ (blue). Center 1036 values represent the mean and error bars represent s.e.m.; $n=4-14$ independent 1037 animals; unpaired $t$-test, ${ }^{* * * *} p<0.0001,{ }^{*} p<0.05$ and $n s p>0.05$.

1038 (G) Relative neovascularization assessed in calcaneal tendon sections stained with 1039 hematoxylin and eosin after different time (as indicated) of the application of 3 1040 punctures with needle (needling, green) or 3 impacts of $3 \mathrm{~mA}$ for $3 \mathrm{sec}$ (blue). Center 1041 values represent the mean and error bars represent s.e.m.; $n=8-15$ independent 1042 animals.

Figure 6-Figure supplement 1. Cytokine expression in the calcaneal tendon of Pycard $^{/-}$mice after galvanic current application.

$1047(A, B)$ Quantitative PCR for $/ / 1 b(A)$ and $C x c / 10(B)$ in the calcaneal tendons of Pycard ${ }^{/-}$ 1048 mice (calculated as $2^{-\Delta \Delta C t}$ ) normalized to the expression in wild type (calculated as $2^{-}$ $104{ }^{\Delta \Delta C t}$ ) after 3 days of 3 impacts of $3 \mathrm{~mA}$ for $3 \mathrm{sec}$. Center values represent the mean and 1050 error bars represent s.e.m.; $n=3-12$ independent animals; unpaired $t$-test. 
1052 Figure 7-Figure supplement 1. Galvanic current do not change properties of the 1053 collagen.

1054 (A) Ultrasound scanning of the right elbow of a patient of with lateral epicondylalgia 1055 after 6 months, with pain and functional impairment. Baseline represents the image 1056 before galvanic current. Discharge represents the image after 4 sessions of 1057 percutaneous electrolysis with an intensity of $3 \mathrm{~mA}$ of galvanic current for $3 \mathrm{sec}, 3$ 1058 times (3:3:3). $6 \mathrm{w}$, represents the image after 6 weeks of the last session of 1059 percutaneous electrolysis.

1060 (B,C) Quantification of the collagen fiber properties (width or length) in calcaneal tendon sections stained with picrosirius red from wild type mice after 3 and 7 days of punctures with needle (needling, green) or 3 impacts of $3 \mathrm{~mA}$ for $3 \mathrm{sec}$ (blue), or in untreated tendons (white). Center values represent the mean and error bars represent s.e.m.; $n=6-8$ independent animals; (B) Mann-Whitney test, (C) non-treated vs needling Mann-Whitney test and non-treated vs percutaneous electrolysis unpaired ttest, ${ }^{* \star *} p<0.0005,{ }^{* *} p<0.005,{ }^{*} p<0.05$ and $n s p>0.05$.

1067

(D) Representative images of calcaneal tendons sections stained with picrosirius red and viewed with polarized light from wild type mice used for quantifying the collagen type I and III in main Figure 7C. Images are after 7 days of punctures with needle

1070 (needling) or 3 impacts of $3 \mathrm{~mA}$ for $3 \mathrm{sec}$ of percutaneous electrolysis, or non-treated 1071 tendons, scale bar $100 \mu \mathrm{m}$.

1072 (E) Raw representative images of second harmonic generation microscopy of 1073 calcaneal tendons from wild-type and $\mathrm{N}_{\mathrm{Irp}} 3^{--}$mice untreated or after 7 days of 3 1074 impacts of $3 \mathrm{~mA}$ for $3 \mathrm{sec}$, scale bar $50 \mu \mathrm{m}$. 
1080 Figure 7-Figure supplement 3. Clamps designed to measure tendon tension.

1081 (A) Image illustrating mice paws after dissection, maintaining intact the calcaneus and 1082 the gastrocnemius/soleus muscles.

1083 (B) Image illustrating mice paws after muscle fibers were removed to expose the 1084 intramuscular tendon fibers of the calcaneal tendon.

1085 (C) Image illustrating the orientation and the position of mice paws in the biochemical 1086 testing of the calcaneal tendon before starting the load.

1087

1088 Figure 7-Figure supplement 4. Accumulation matrix of the algorithm based on the 1089 Hough transform from collagen fibers imaged with second harmonic generation 1090 microscopy of calcaneal tendons from wild-type and N/rp3 $3^{-/}$mice after 7 days of 3 1091 impacts of $3 \mathrm{~mA}$ for $3 \mathrm{sec}$; scale bar $50 \mu \mathrm{m}$.

1092 
SOURCE DATA FILES LEGENDS

1094

1095 Figure 1-sorce data 1. Raw data of panels of Figure 1.

1096

1097

Figure 2-source data 1. Uncropped Western blots with the relevant bands boxed 1098 from Figure 2D.

1099

1100 Figure 2-source data 2. Original files of the full raw unedited blots from Figure 1101 2D.

1102

1103

Figure 2-source data 3. Raw data of panels from Figure 2.

1104

1105

Figure 3-source data 1. Raw data of panels from Figure 3.

1106

1107

Figure 4-source data 1. Raw data of panels from Figure 4C,D.

1108

1109

Figure 4-source data 1. Representation of raw data of panels from Figure 4C,D.

1110

1111

Figure 5-source data 1. Raw data of panels from Figure 5.

1112

1113 Figure 6-source data 1. Raw data of panels from Figure 6.

1114

1115 Figure 7-source data 1. Raw data of panels from Figure 7.

1116

1117

1118 
A

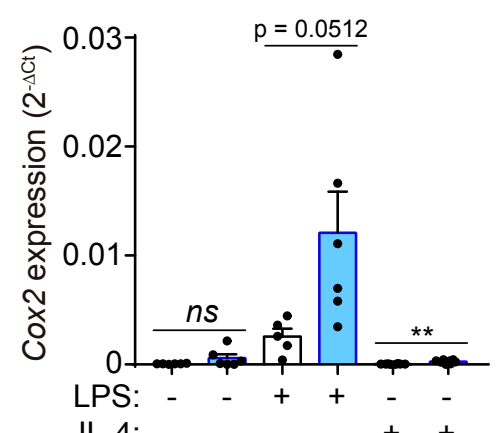

Intensity (mA): $-12-12-12$

Time (s): $-6-6-6$

Impacts (no.): $-2-2-2$

B

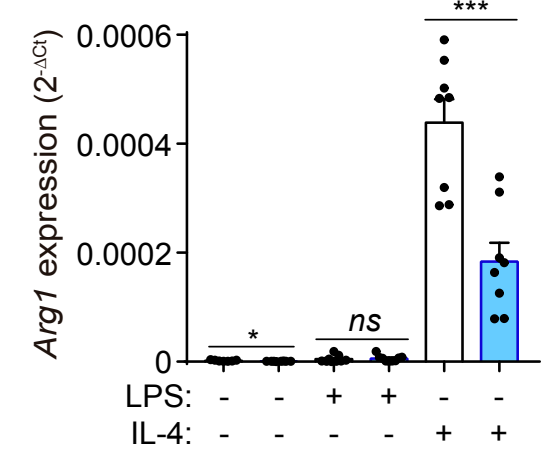

Intensity $(\mathrm{mA}):-12-12-12$

Time (s): $-6-6-6$

Impacts (no.): $-2-2-2$

C

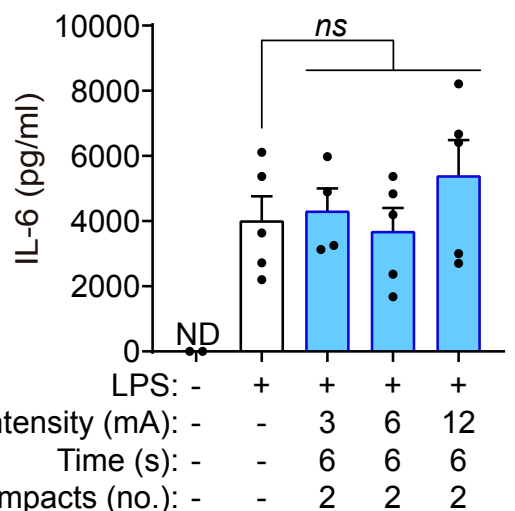

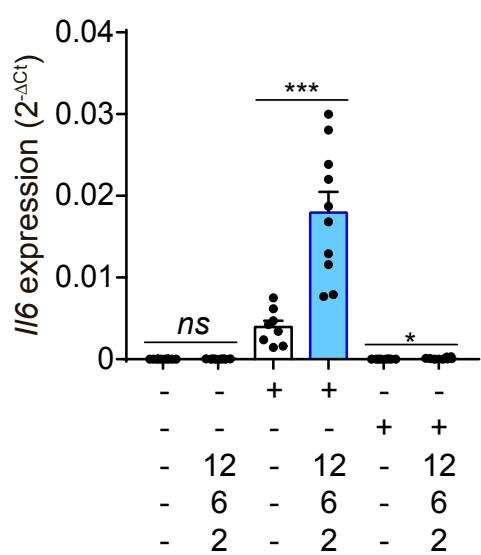
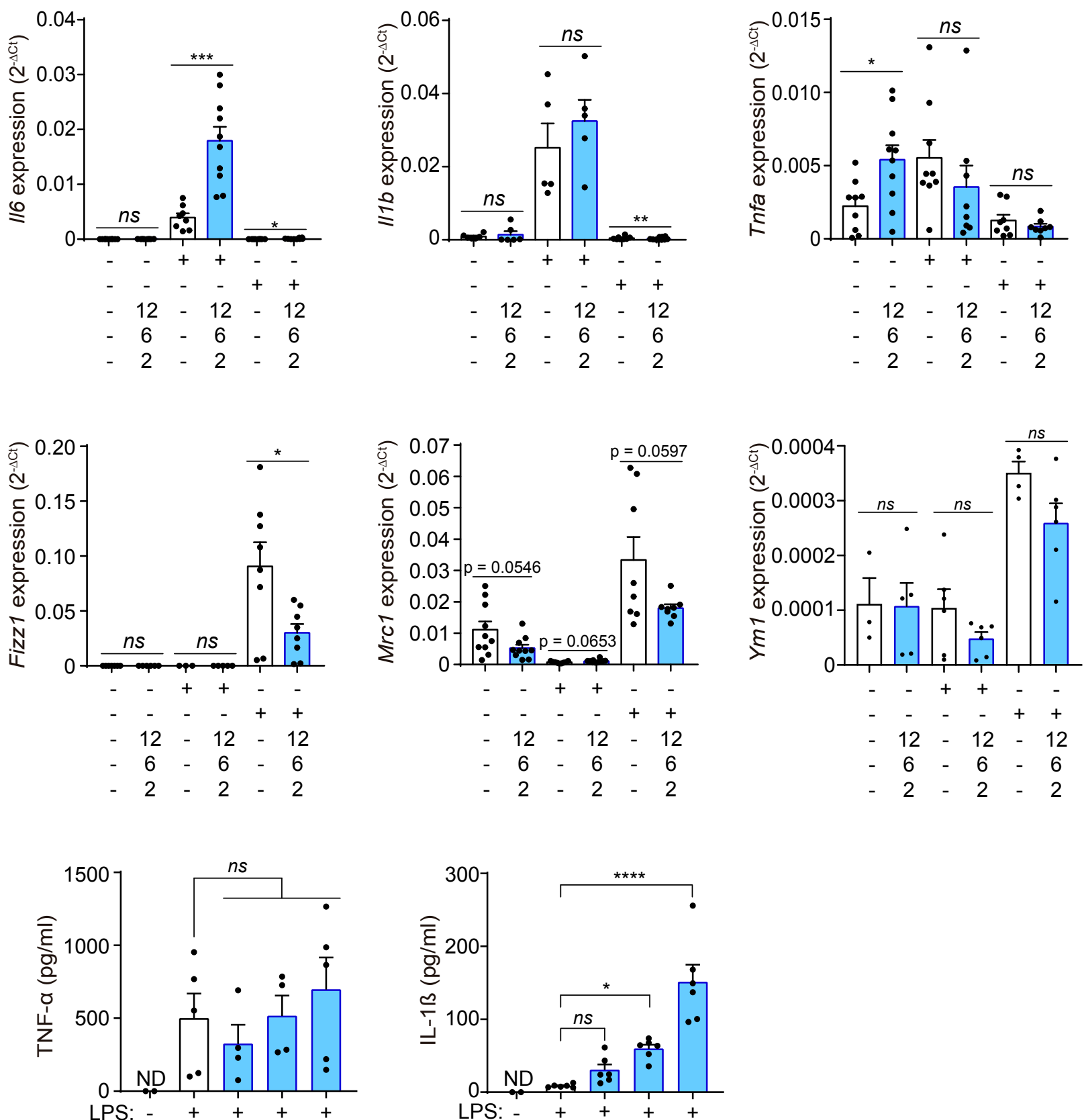

Intensity $(\mathrm{mA})$ :

Time (s):

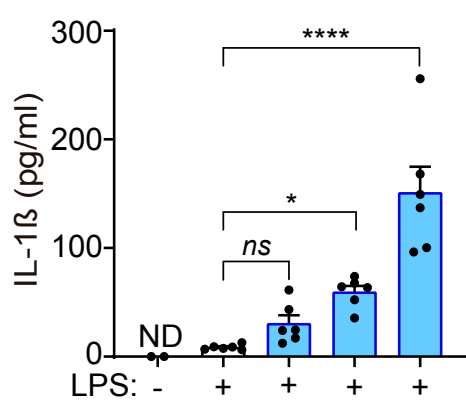

Impacts (no.):
Figure 1 
A

Figure 2

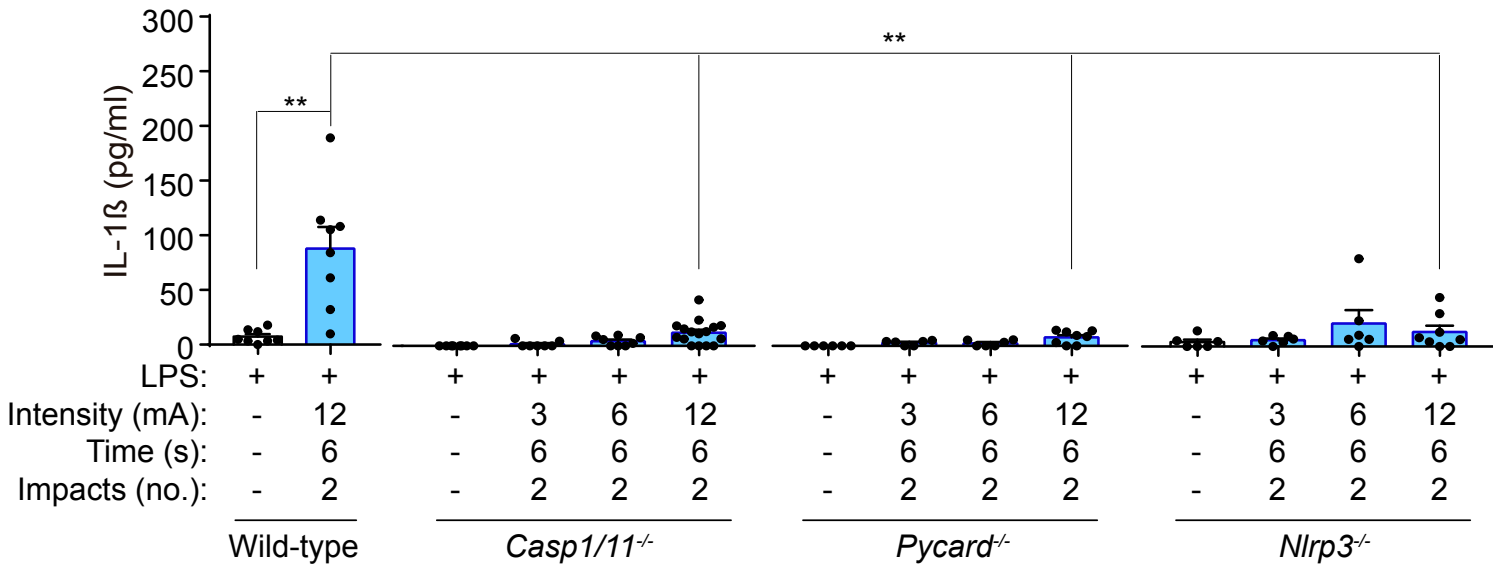

B

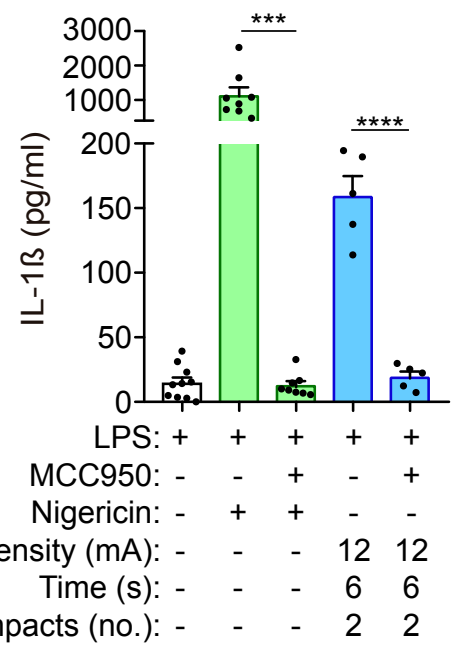

C

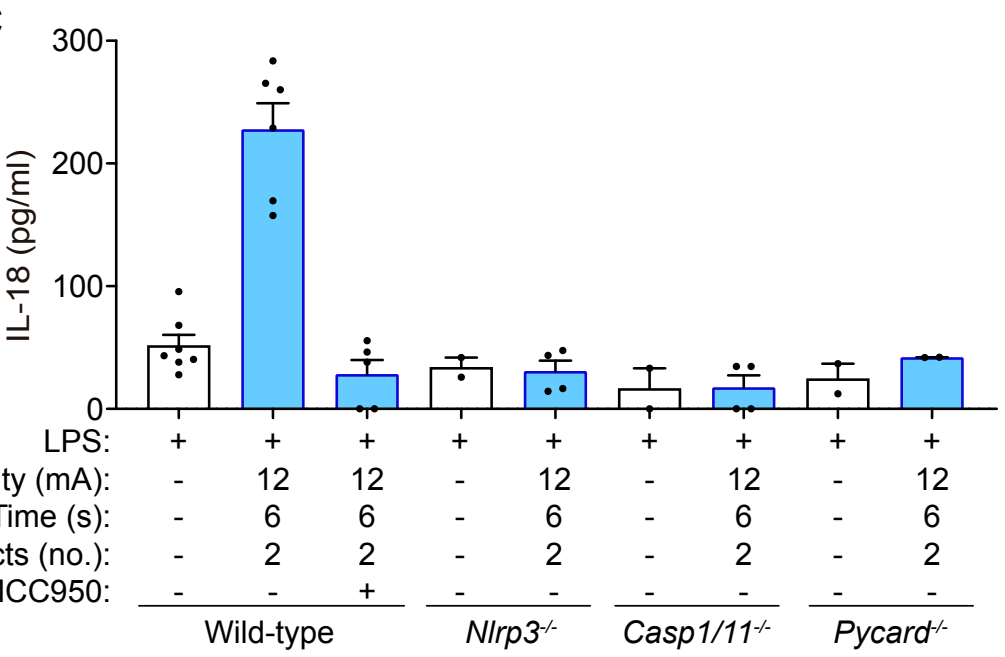

D

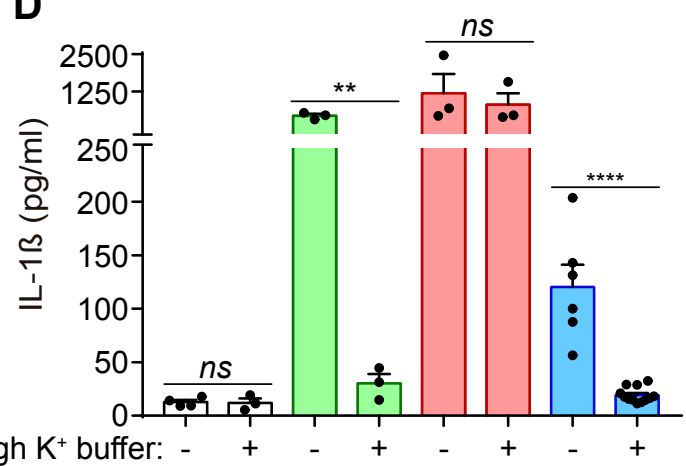

E

$\mathbf{F}$

पLPS $\quad$ LPS+Clostridium difficile toxin B $\square$ LPS+Nigericin $\square$ LPS +2 impacts of galvanic current (12mA-6s)
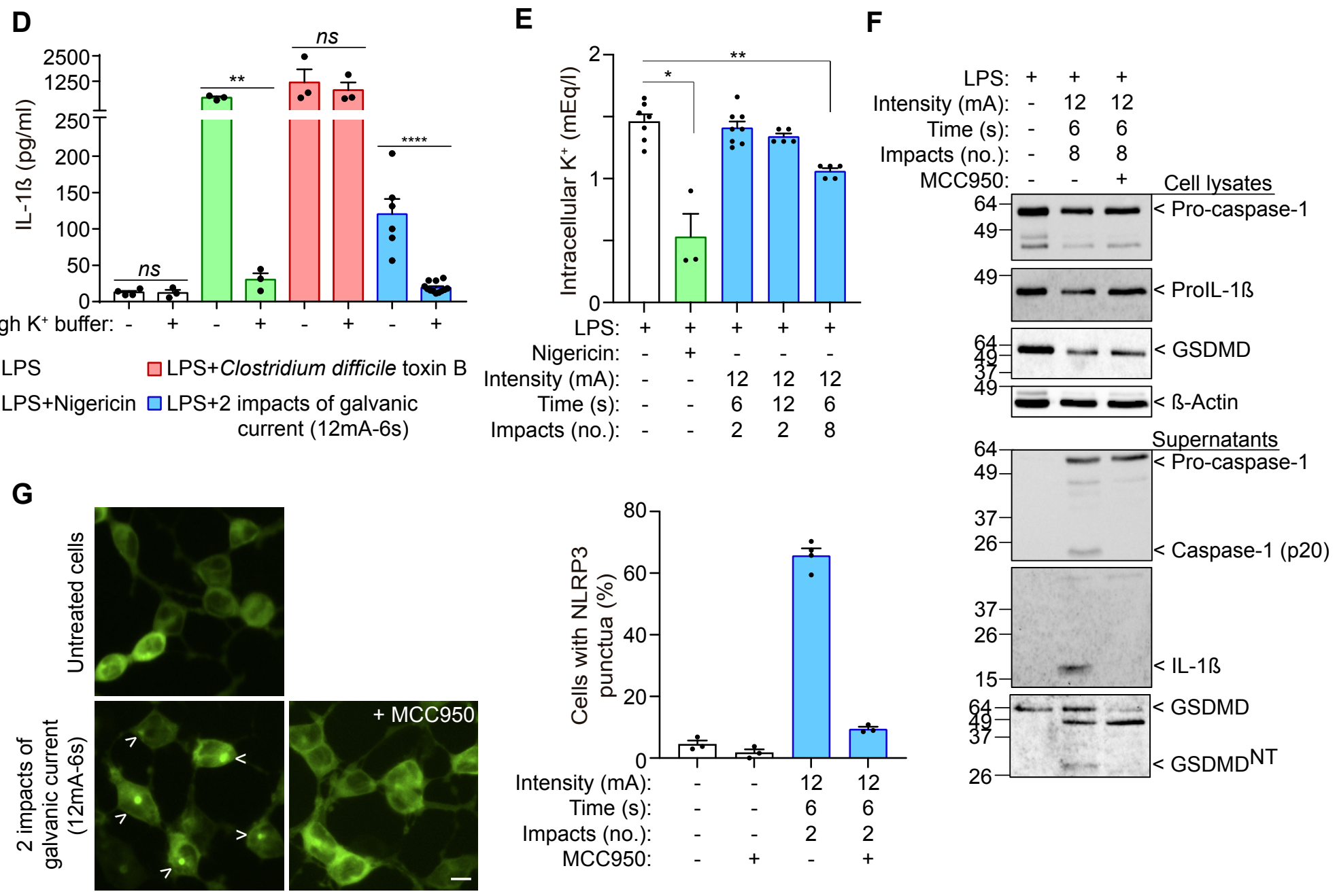
A

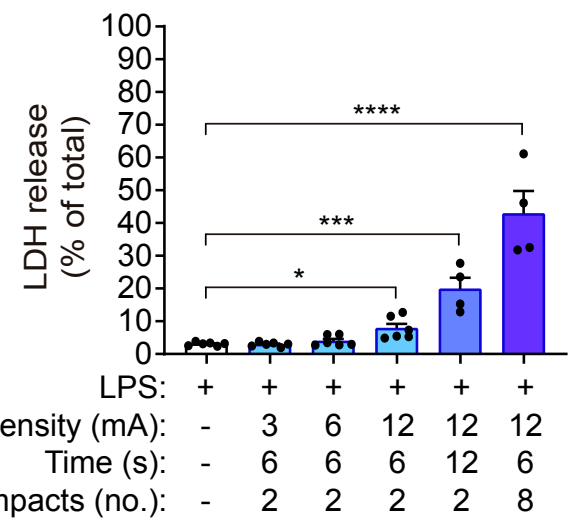

C

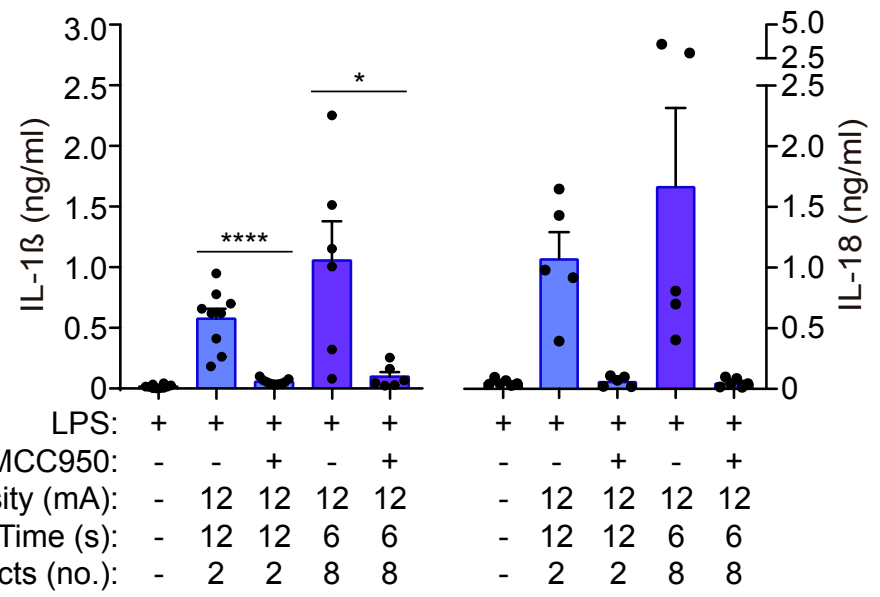

E

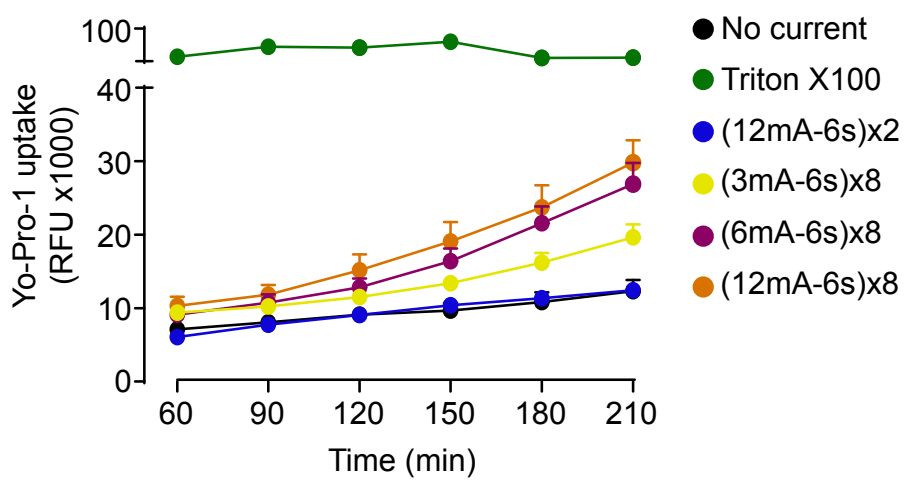

F

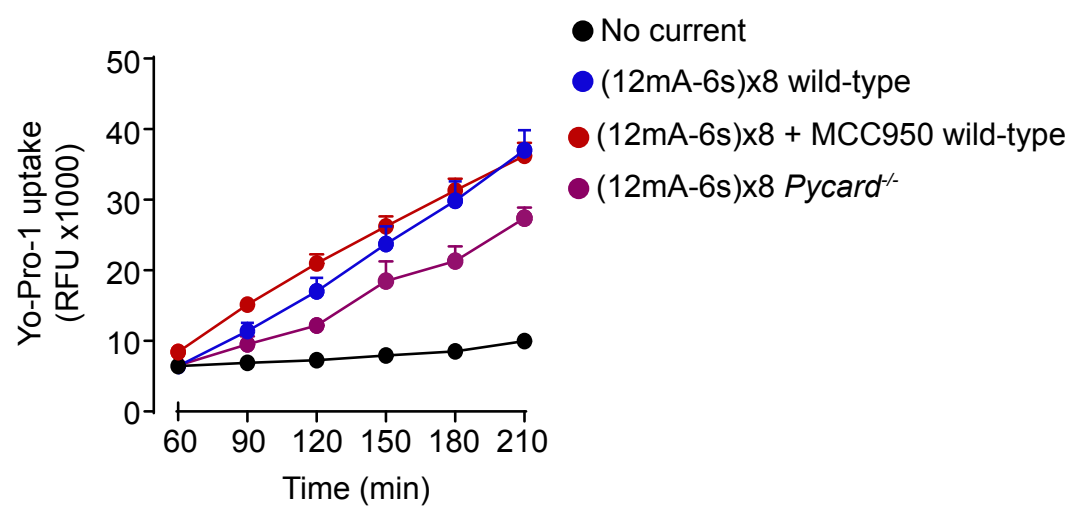

B

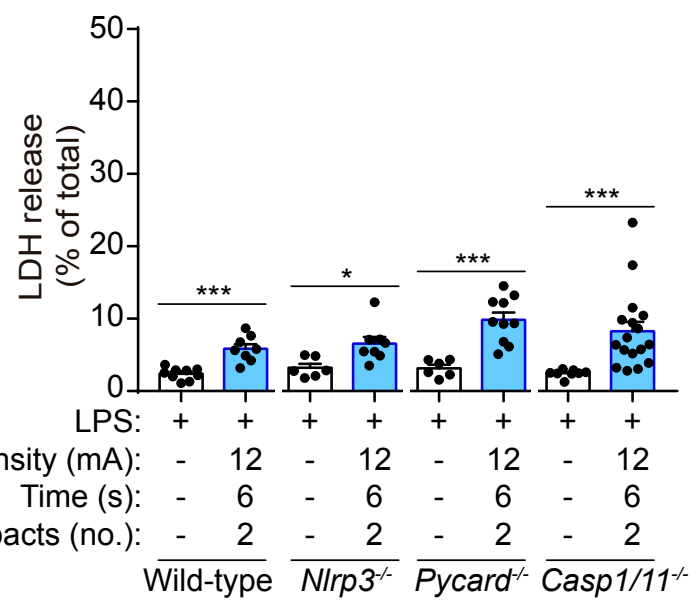

D
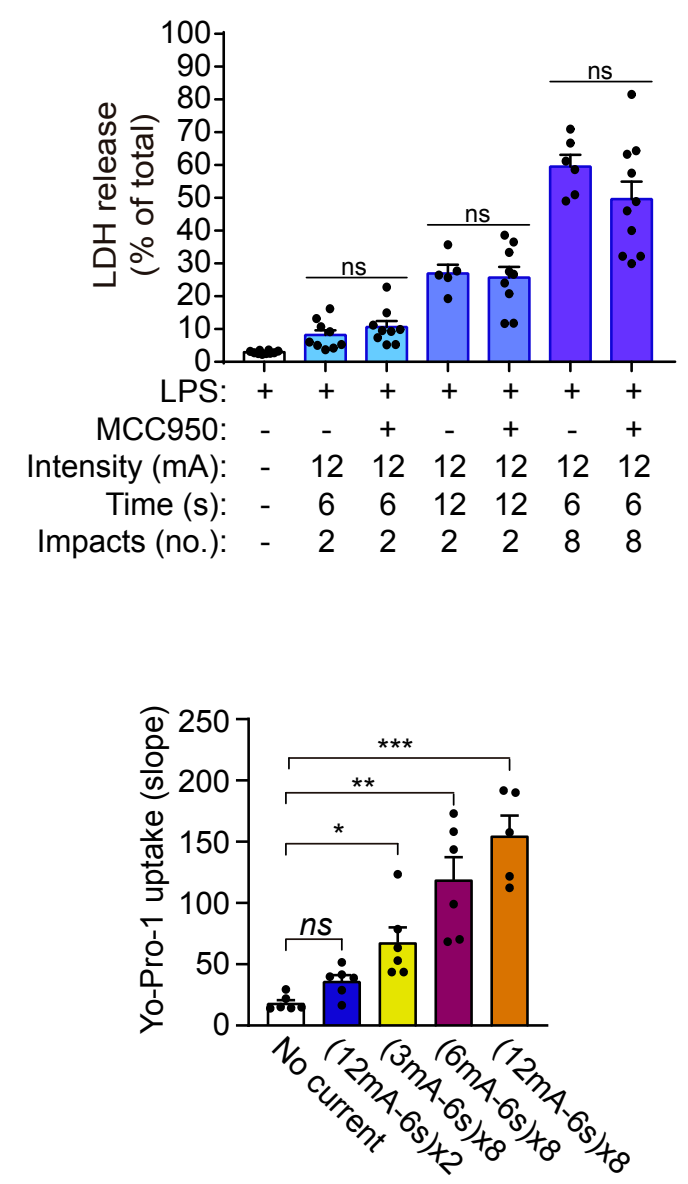
Figure 4

A

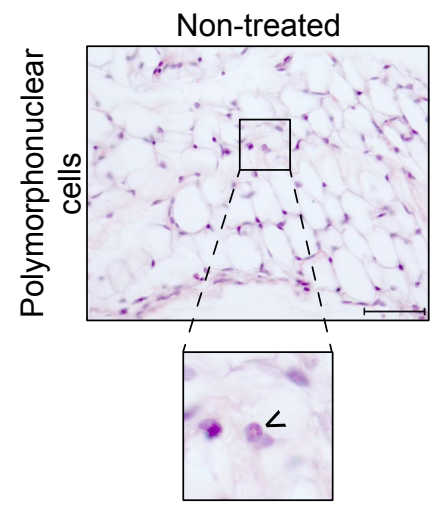

C

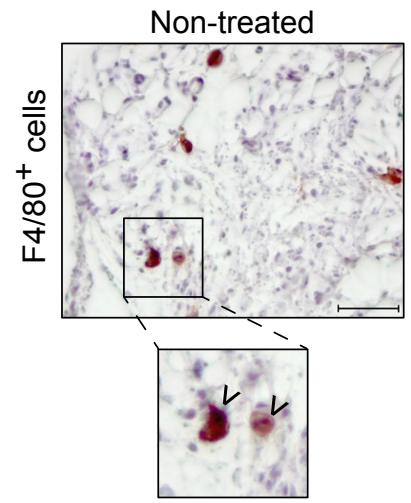

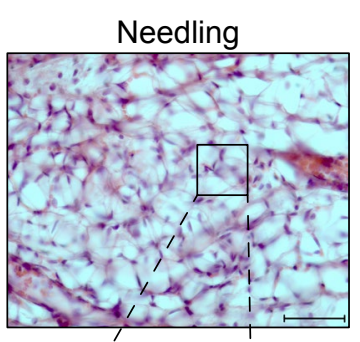
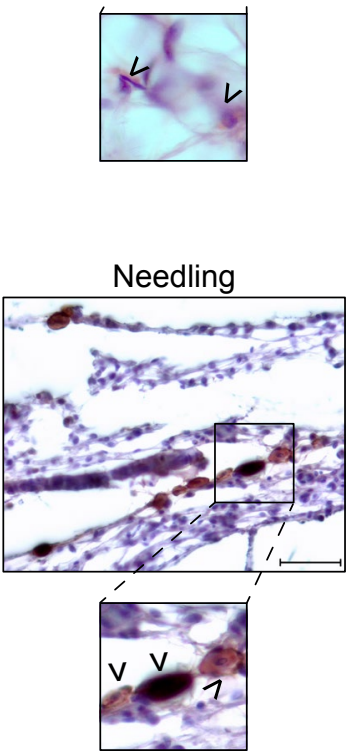

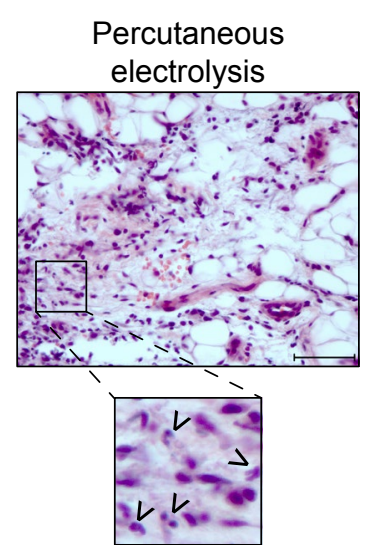

B

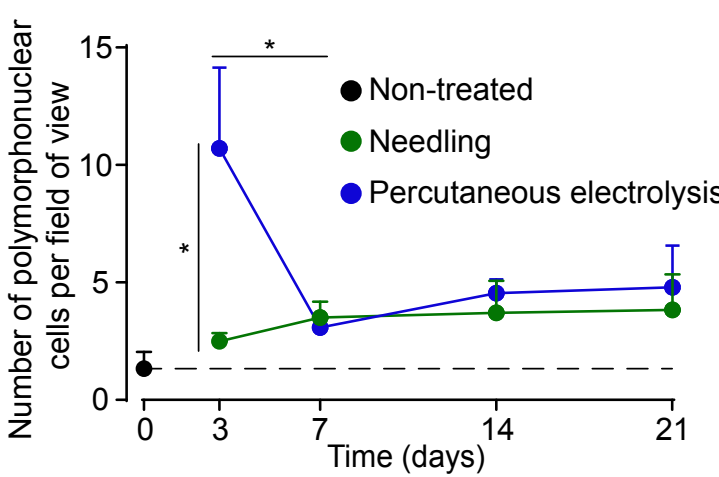

D
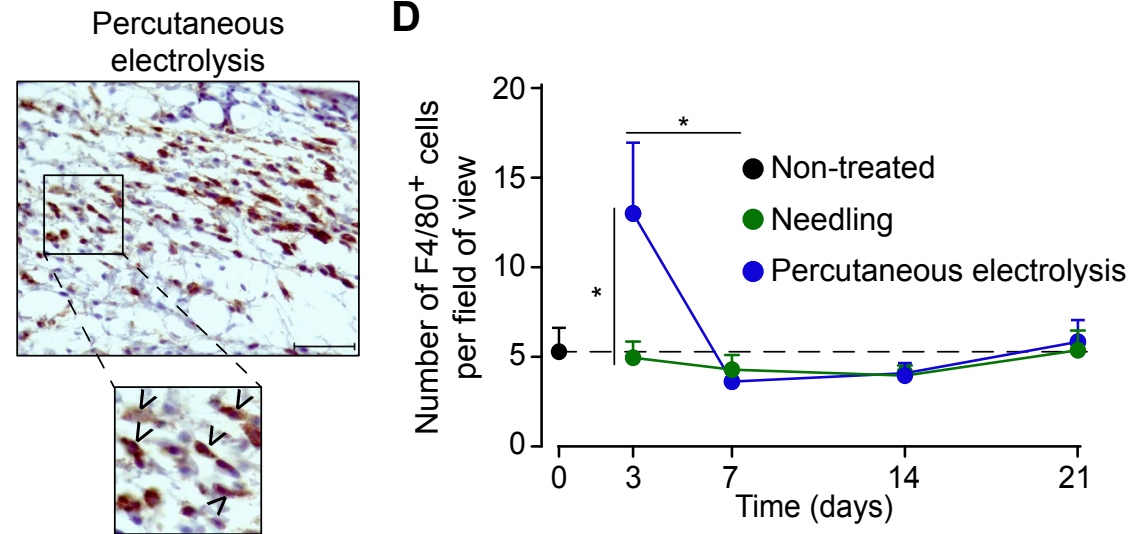
A

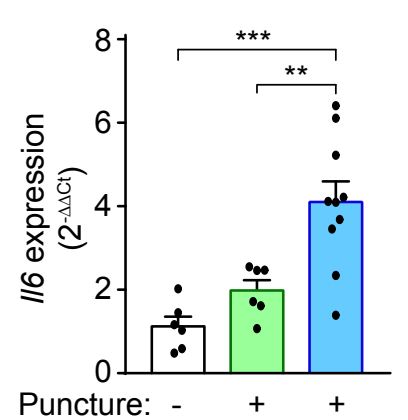
Intensity $(\mathrm{mA}):-\quad-3$

Time (s): - - 3 Impacts (no.): - $\quad$ - 3
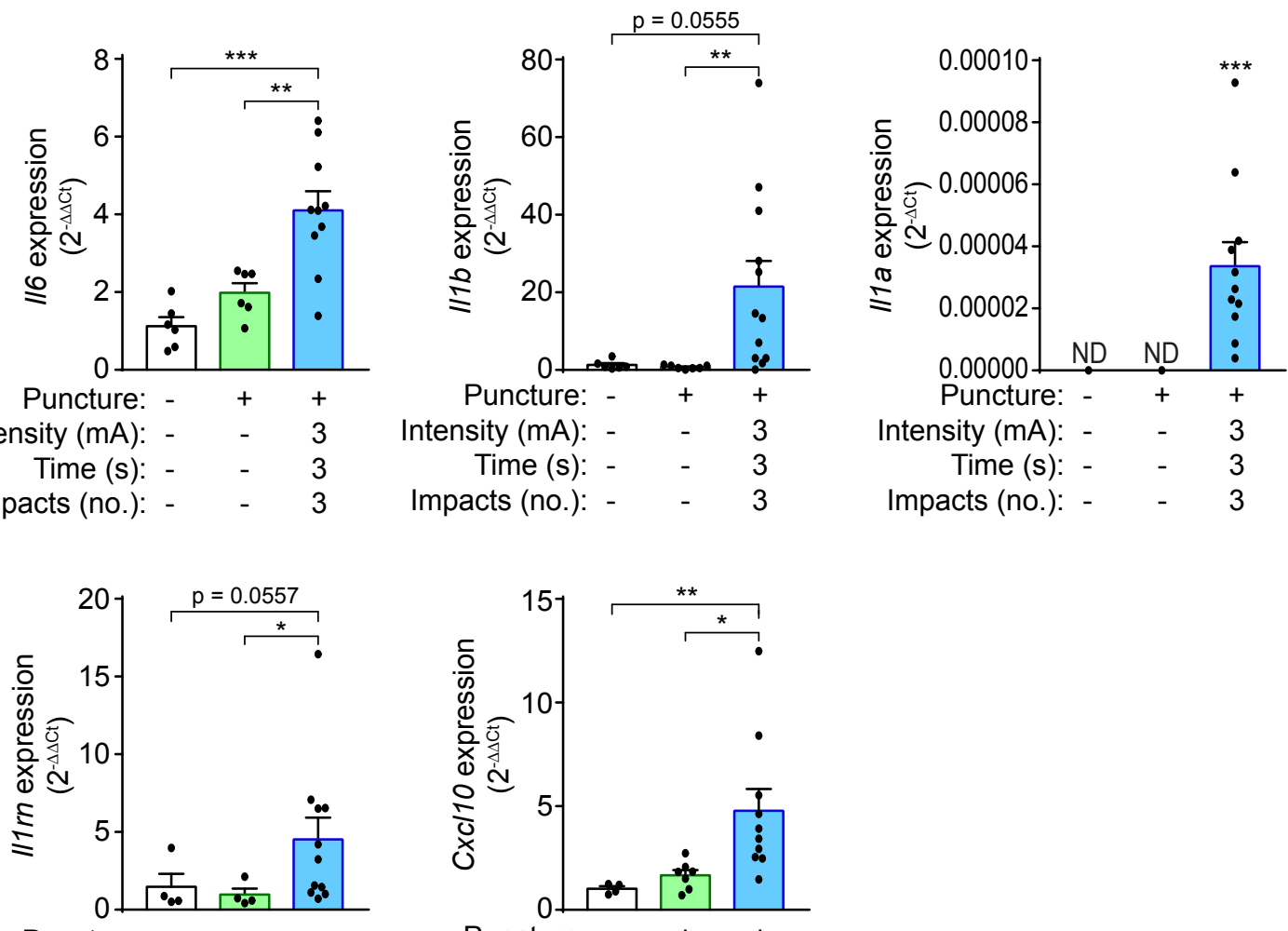

Puncture: -

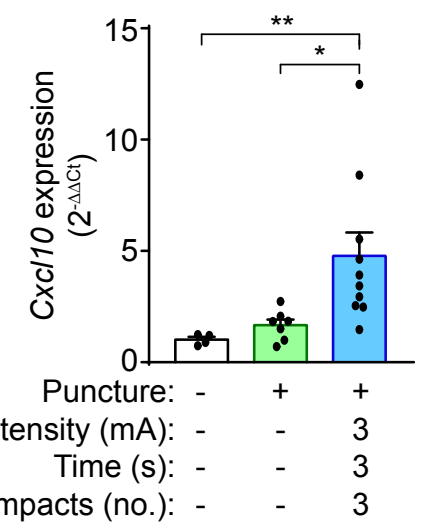

B
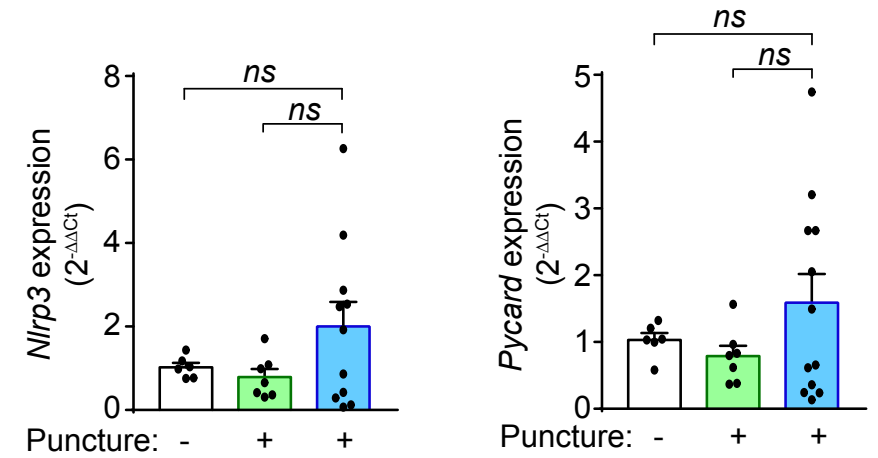
Intensity $(\mathrm{mA}):-\quad-3$

Time (s): - $\quad-\quad 3$ Impacts (no.): - $\quad$ - 3 Intensity (mA): - $\quad-3$
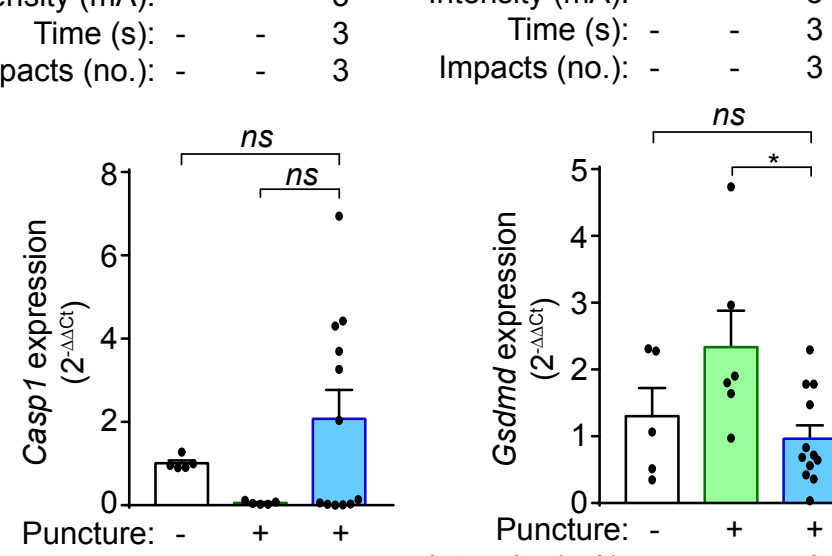
Impacts (no.): - $\quad$ - 3 Intensity $(\mathrm{mA})$ : - $\quad$ - 3 Time (s): - $\quad-\quad 3$ Impacts (no.): - $\quad$ - 3

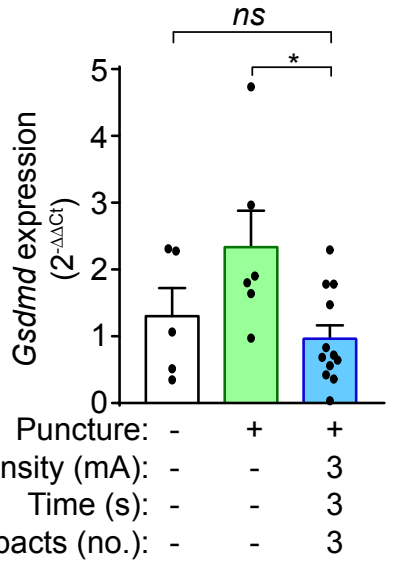


A
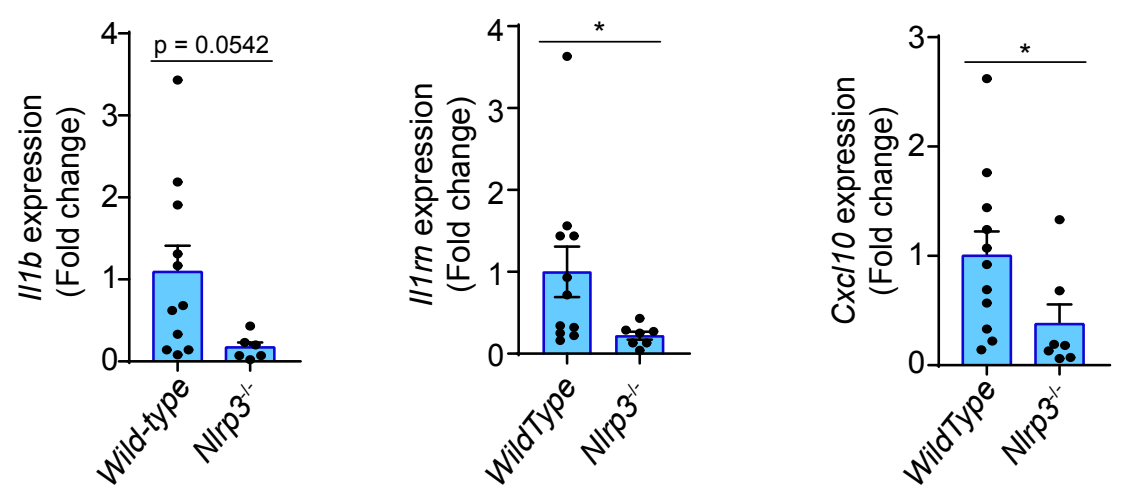

B
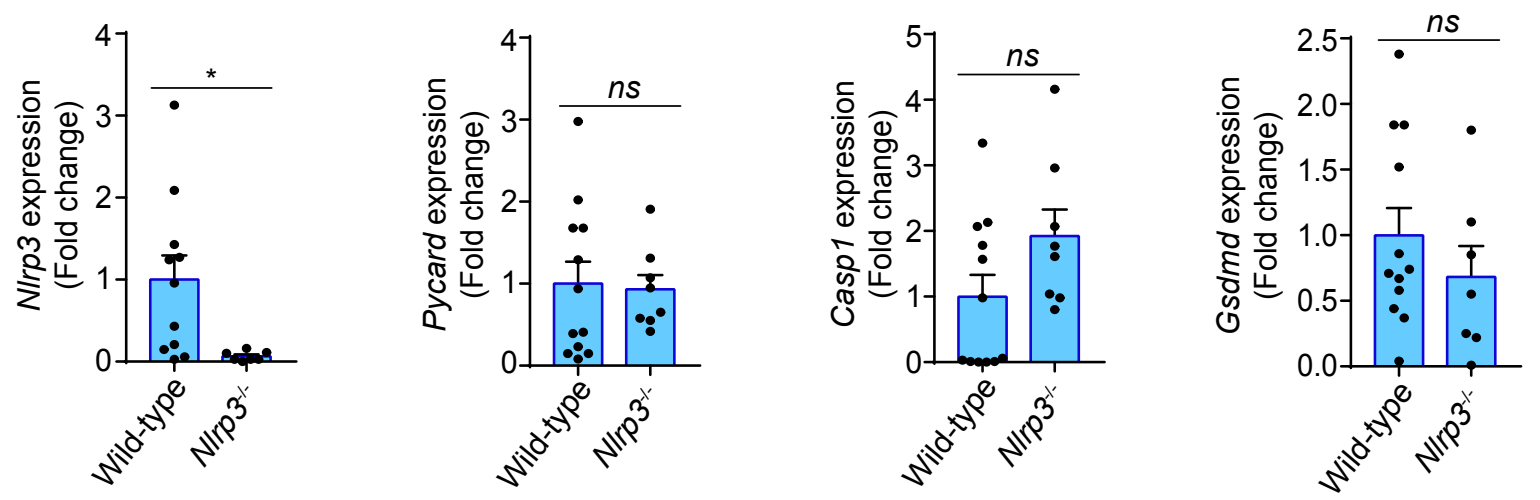

C

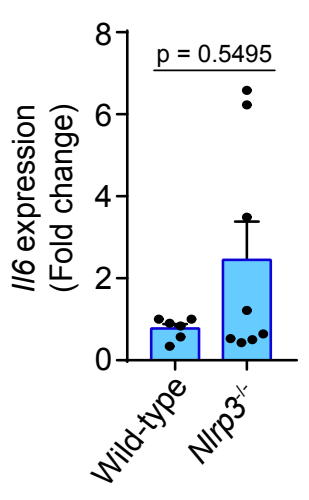

D
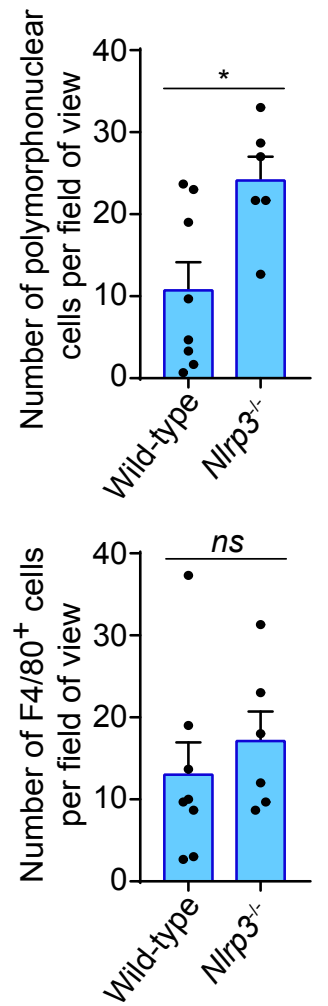
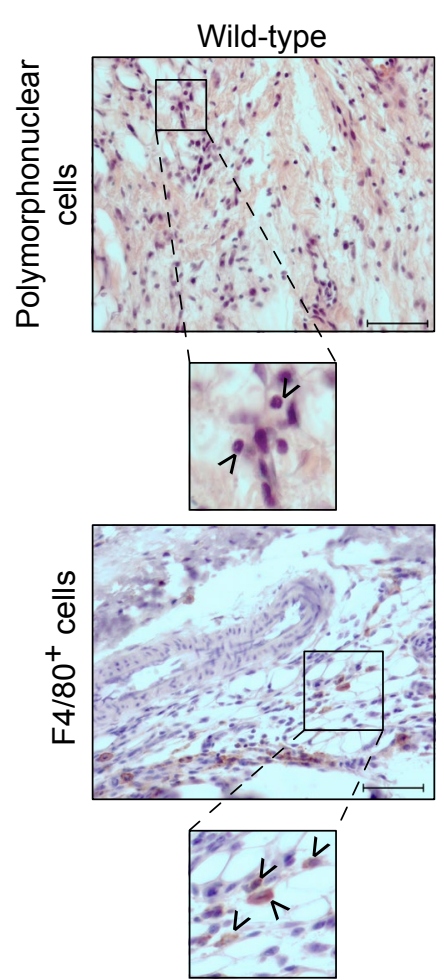

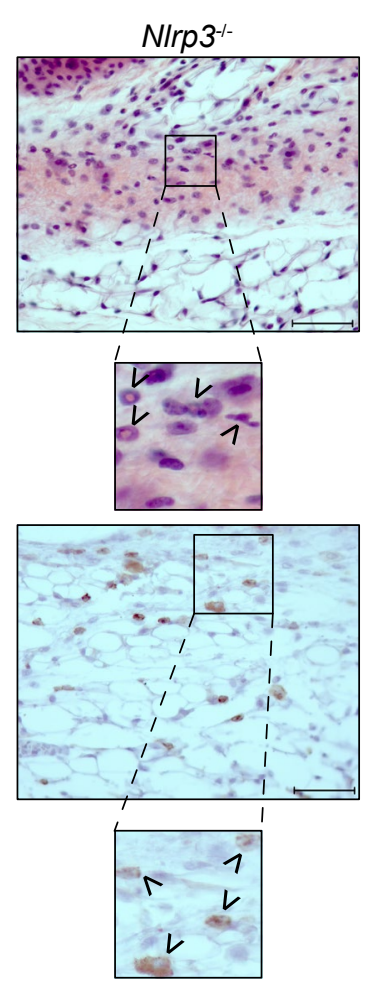


$\square$ Non-treated

$\square$ Needling

$\square$ Percutaneous electrolysis

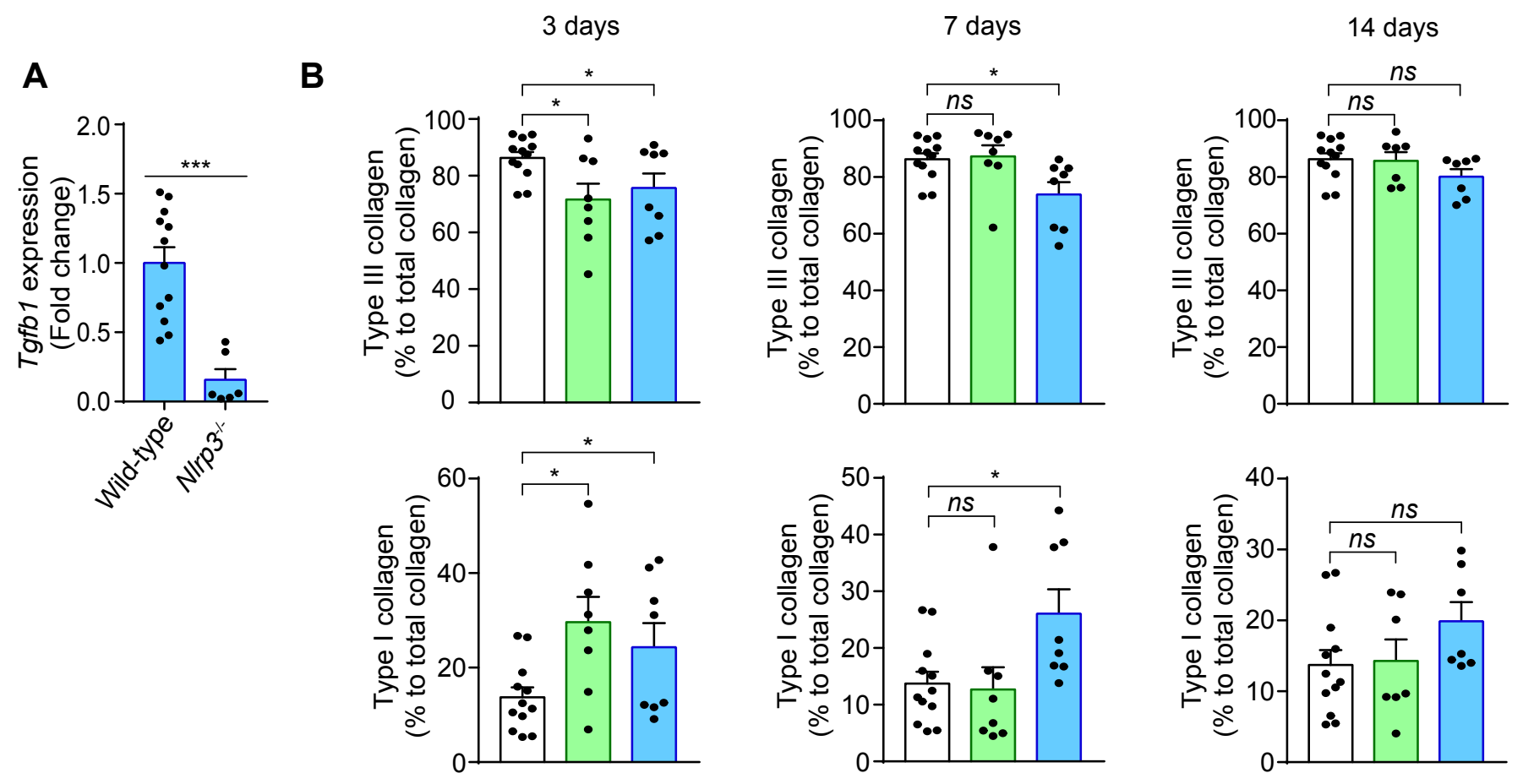

C

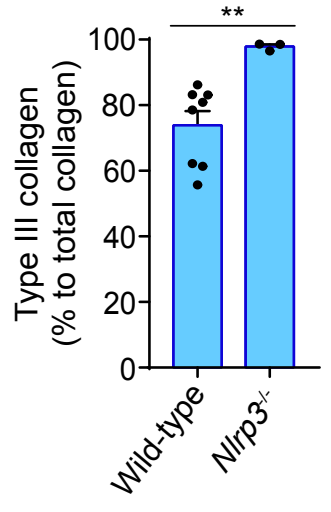

D
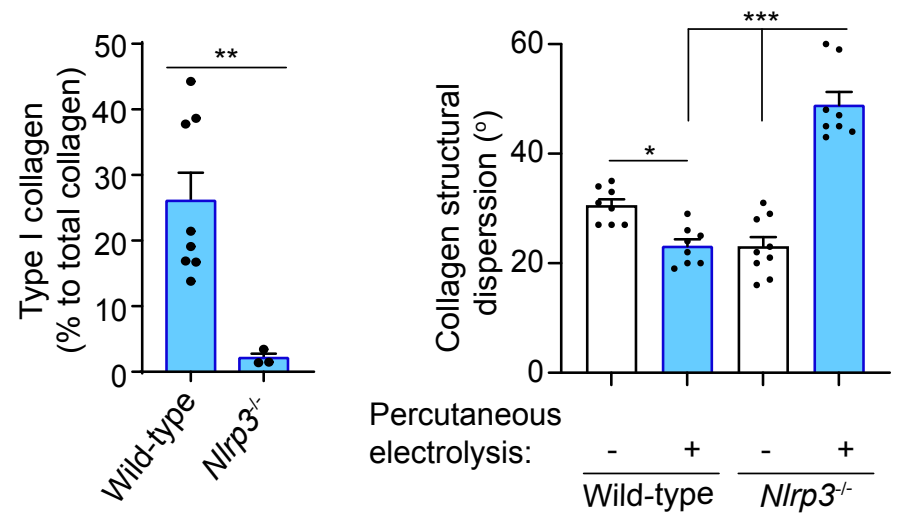

Percutaneous

electrolysis: $\frac{-}{\text { Wild-type }} \frac{-}{N / r p 3^{-1-}}$

E

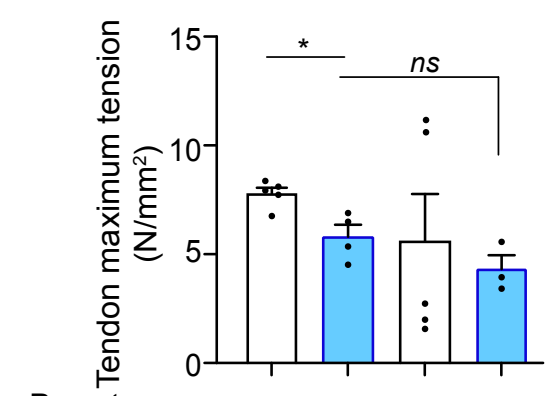

Percutaneous electrolysis:

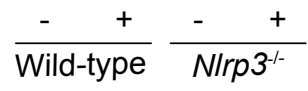

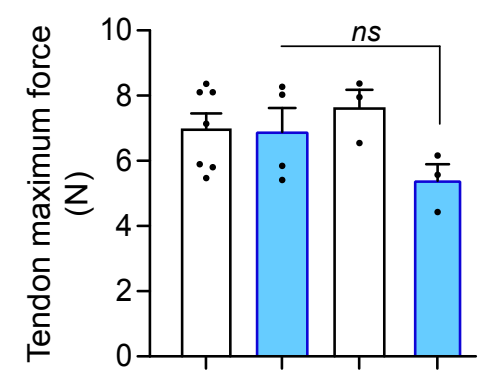

Percutaneous electrolysis:

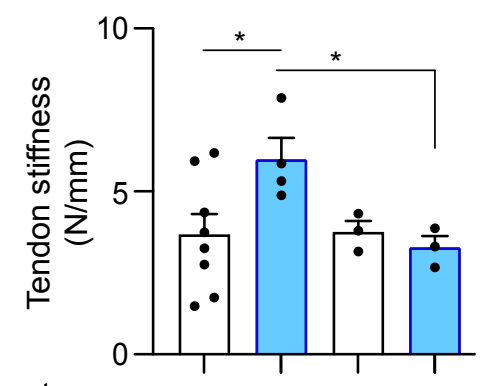

Percutaneous electrolysis:

$\overline{\text { Wild-type }} \overline{\text { NIrp3 }^{-/-}}$ 
Figure 1-figure supplement 1

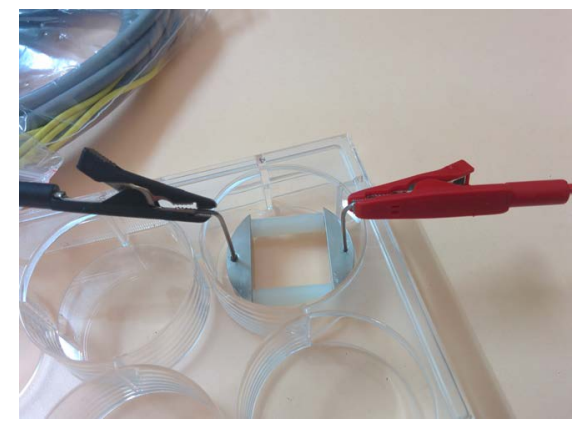




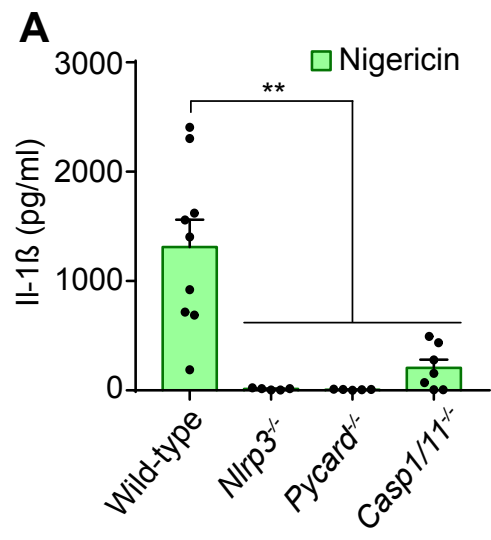

B

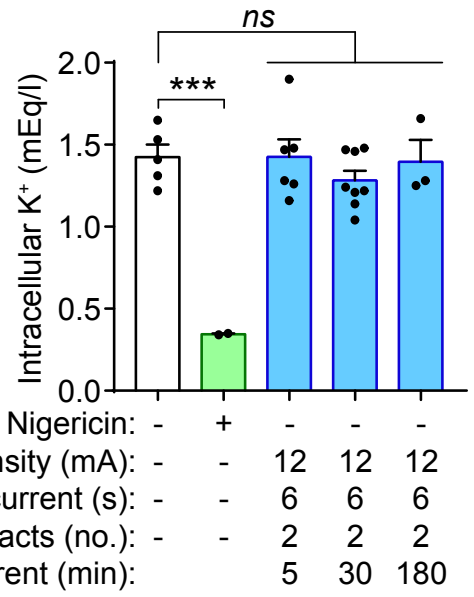


Figure 4-figure supplement 1

A
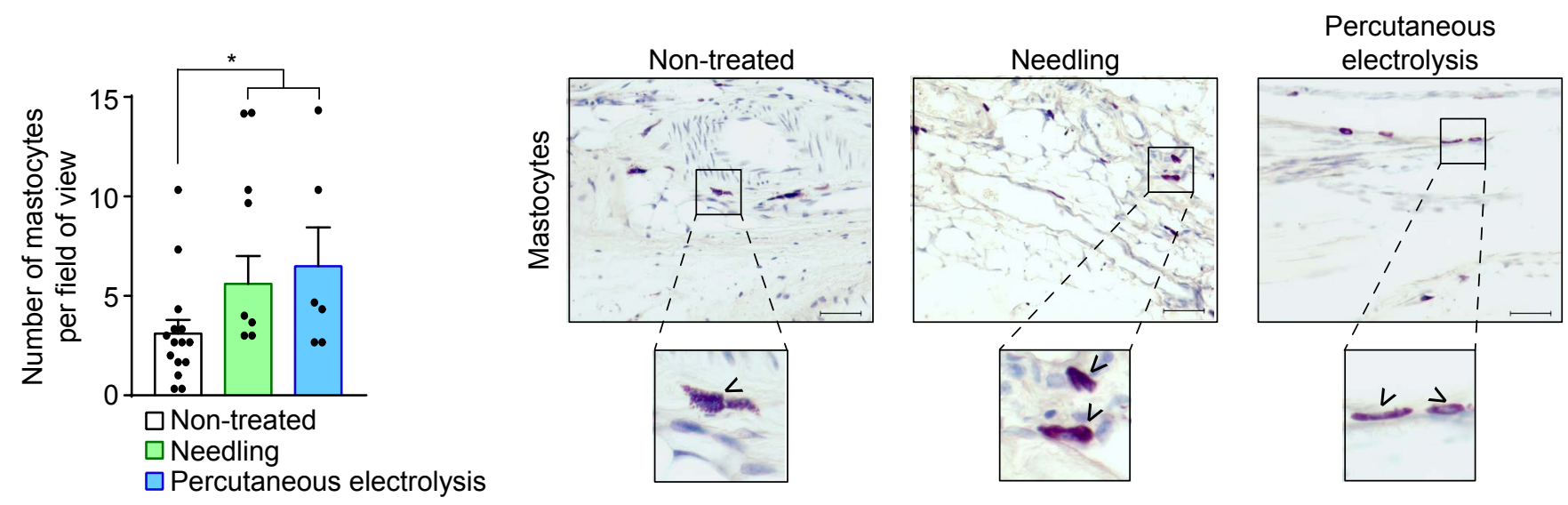

B
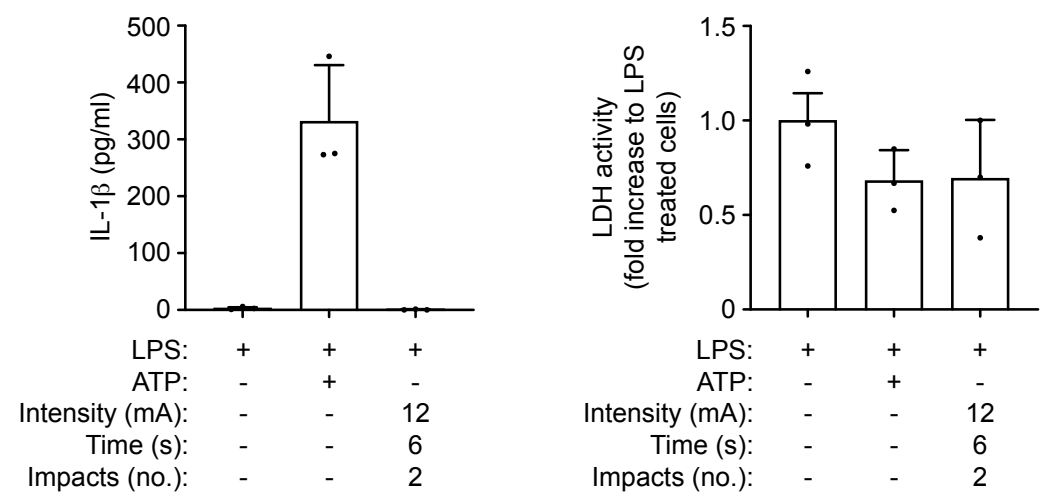

C
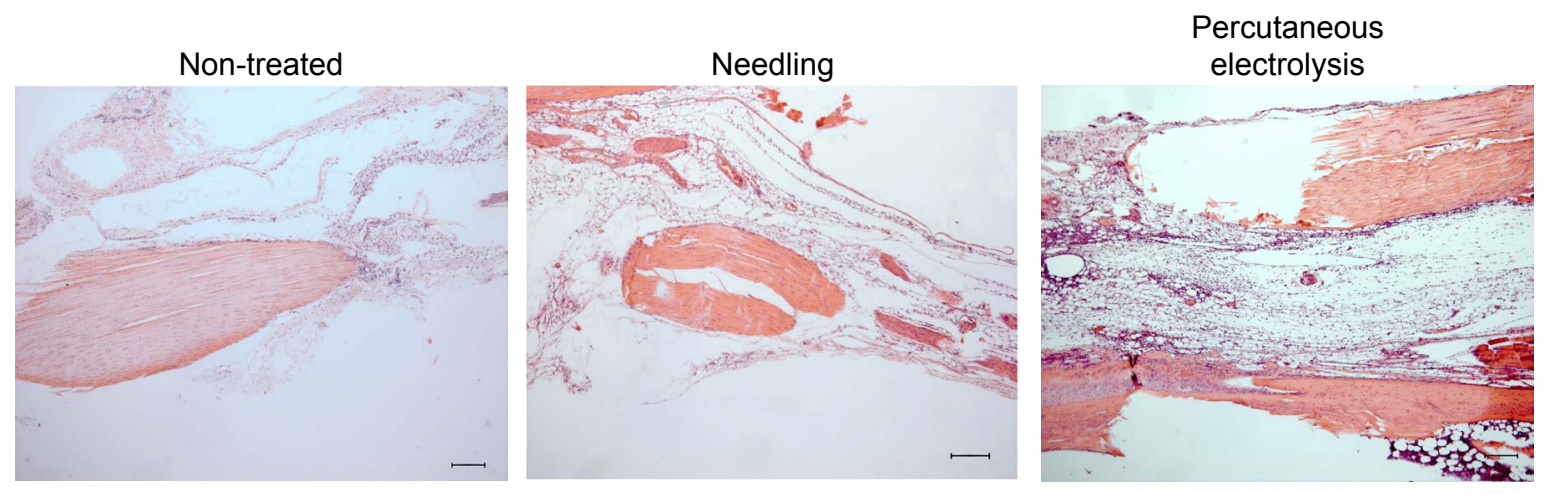

D

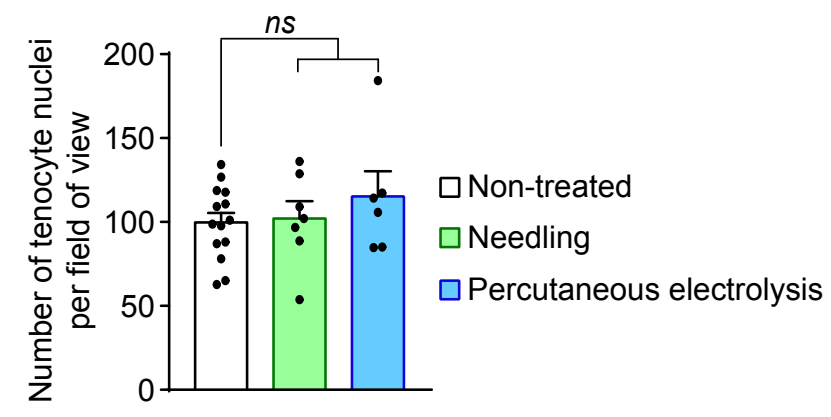

F

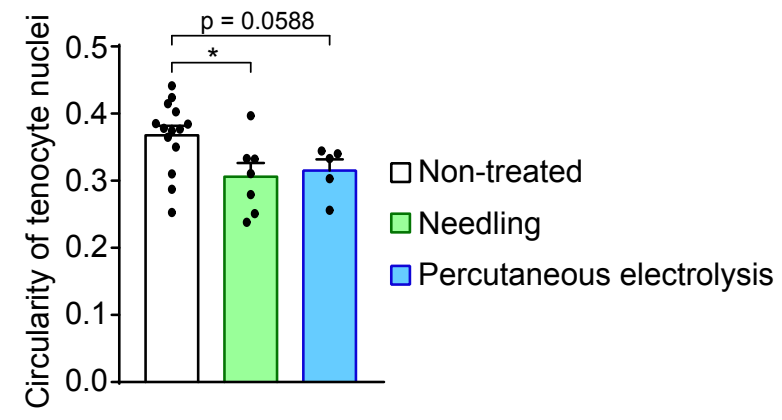

E

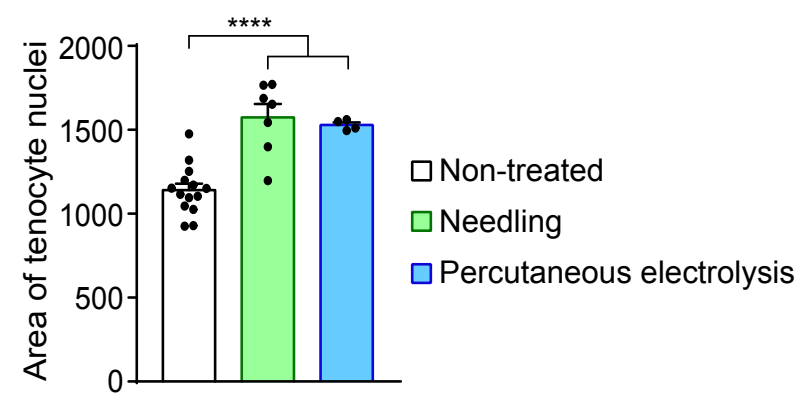

G

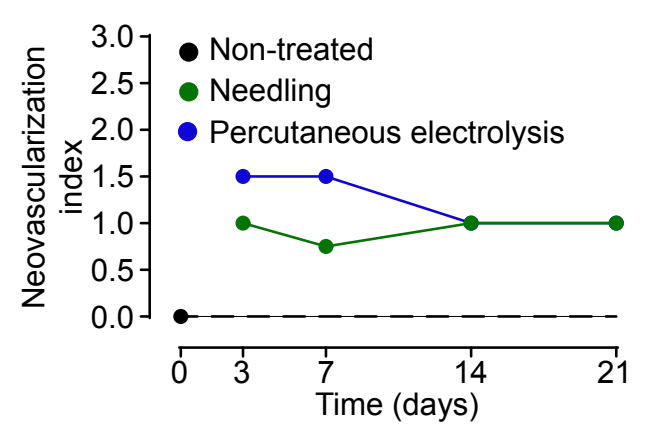


Figure 6-figure supplement 1

A

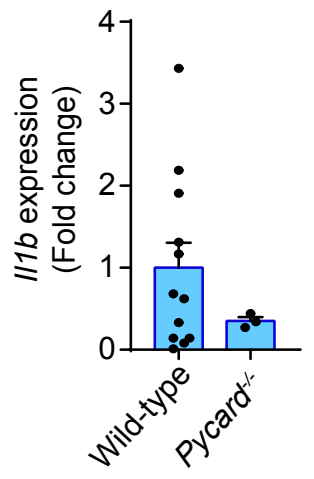

B

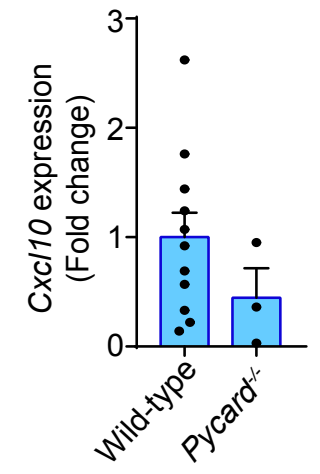


Figure 7-figure supplement 1

A

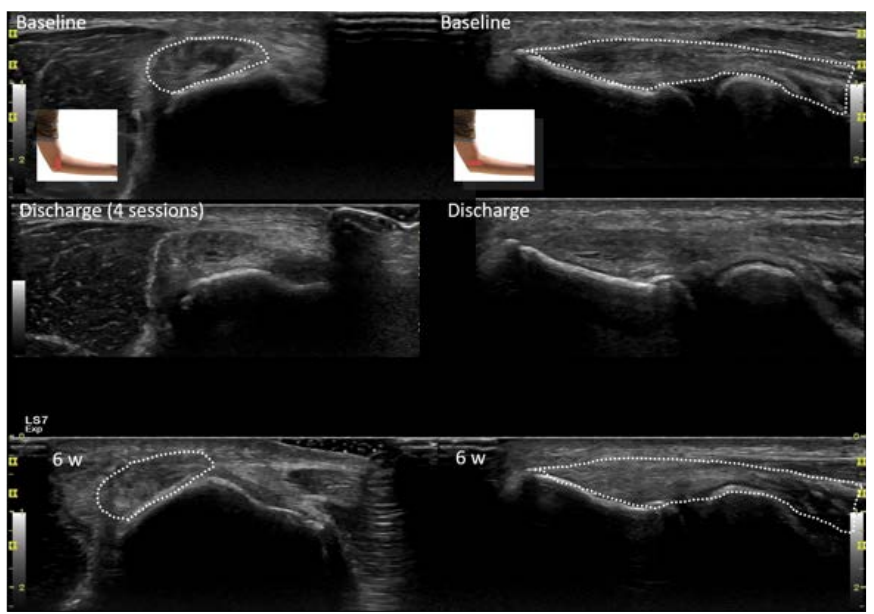

B

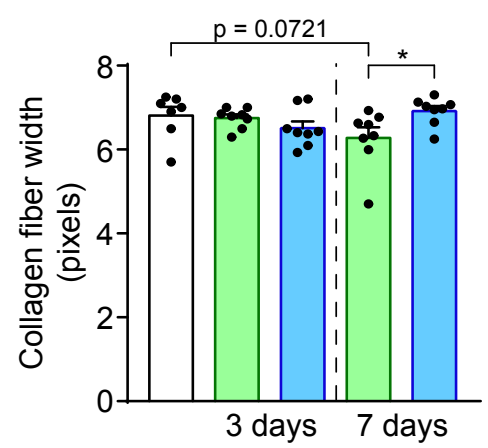

D

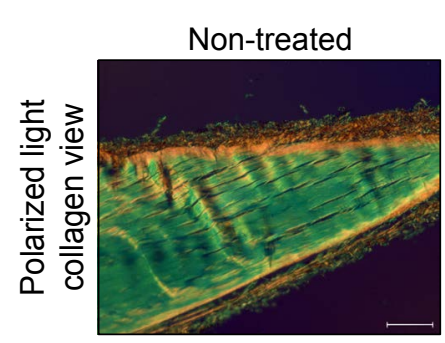

$\square$ Non-treated

$\square$ Needling

$\square$ Percutaneous electrolysis

C

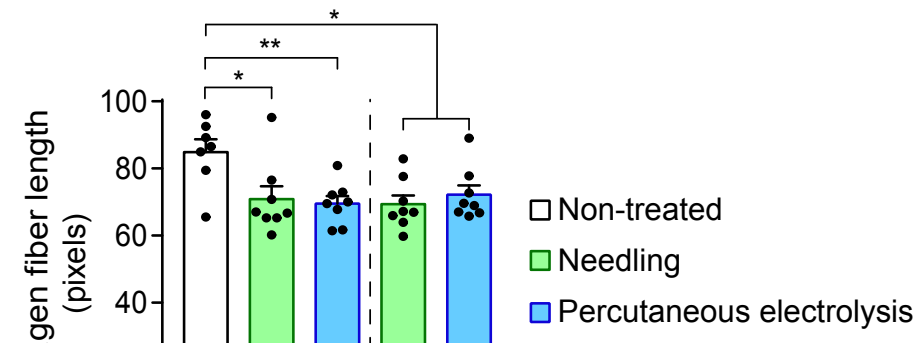

Percutaneous electrolysis

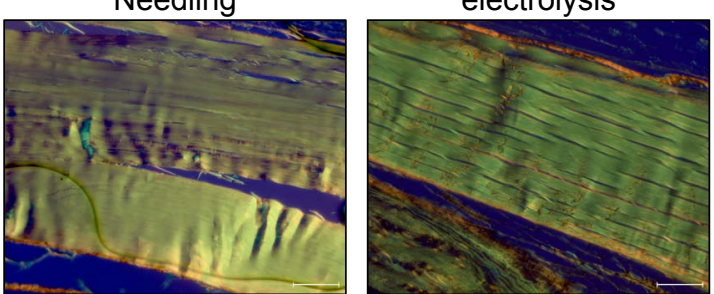

Non-treated
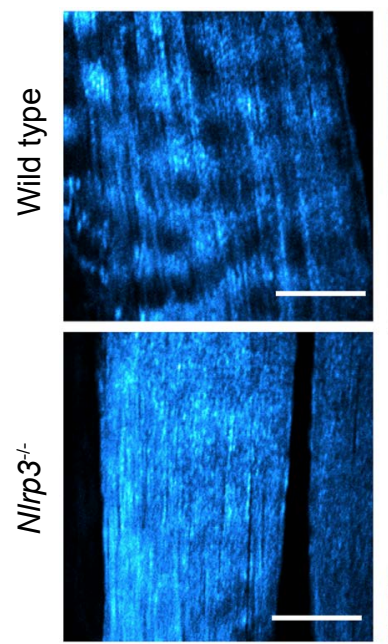

Percutaneous electrolysis

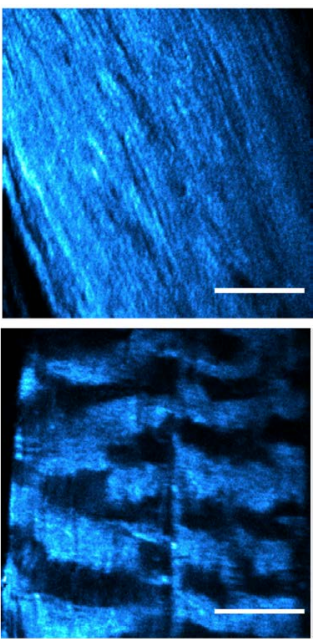


Polymorphonuclear and macrophage infiltration IL-6 production
NLRP3 independent effects

Tendon damage

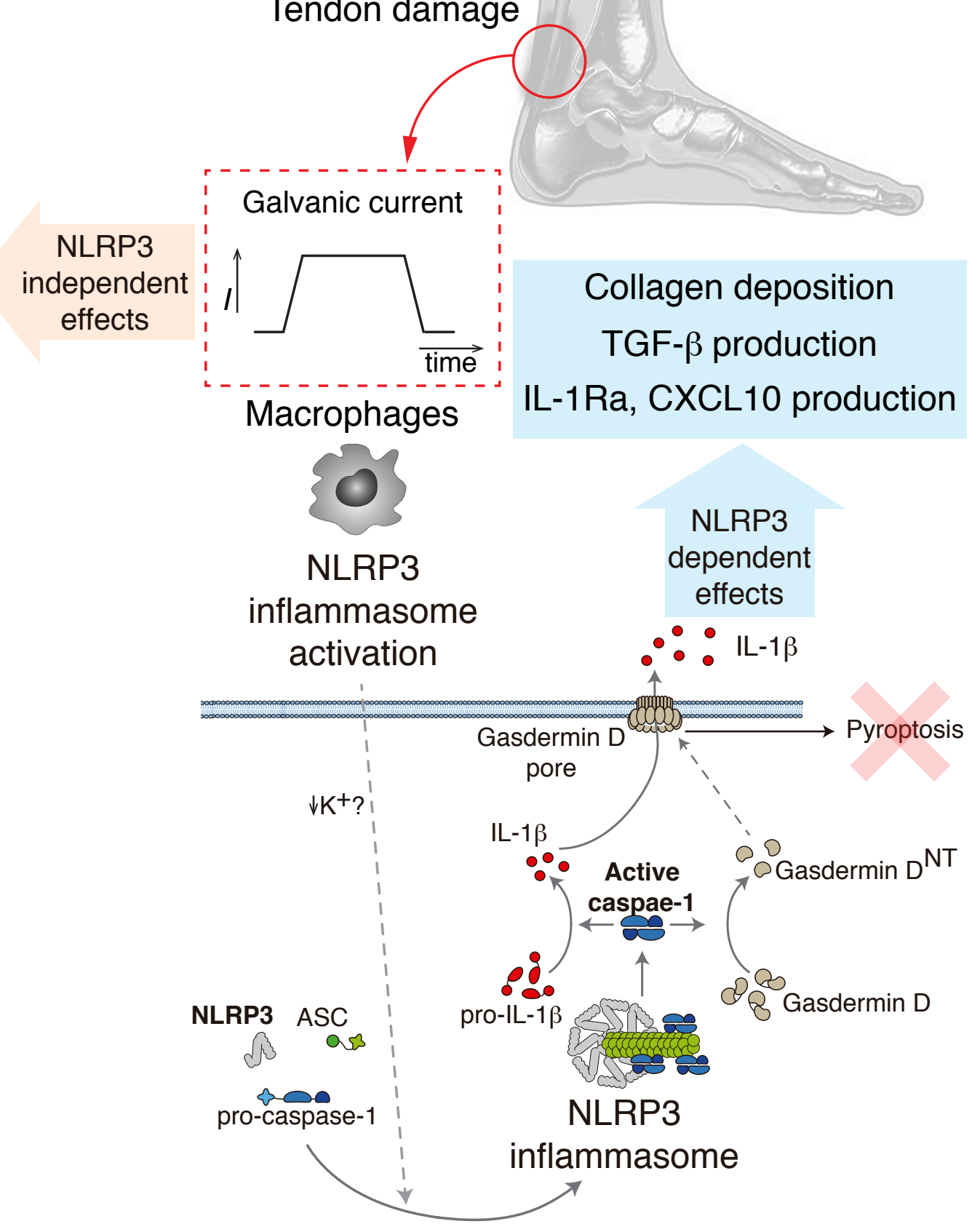


Figure 7-figure supplement 3

A

B
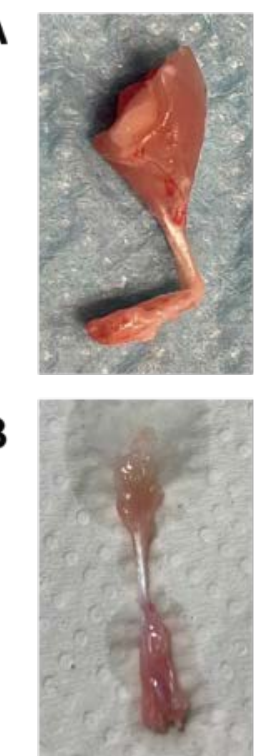

C

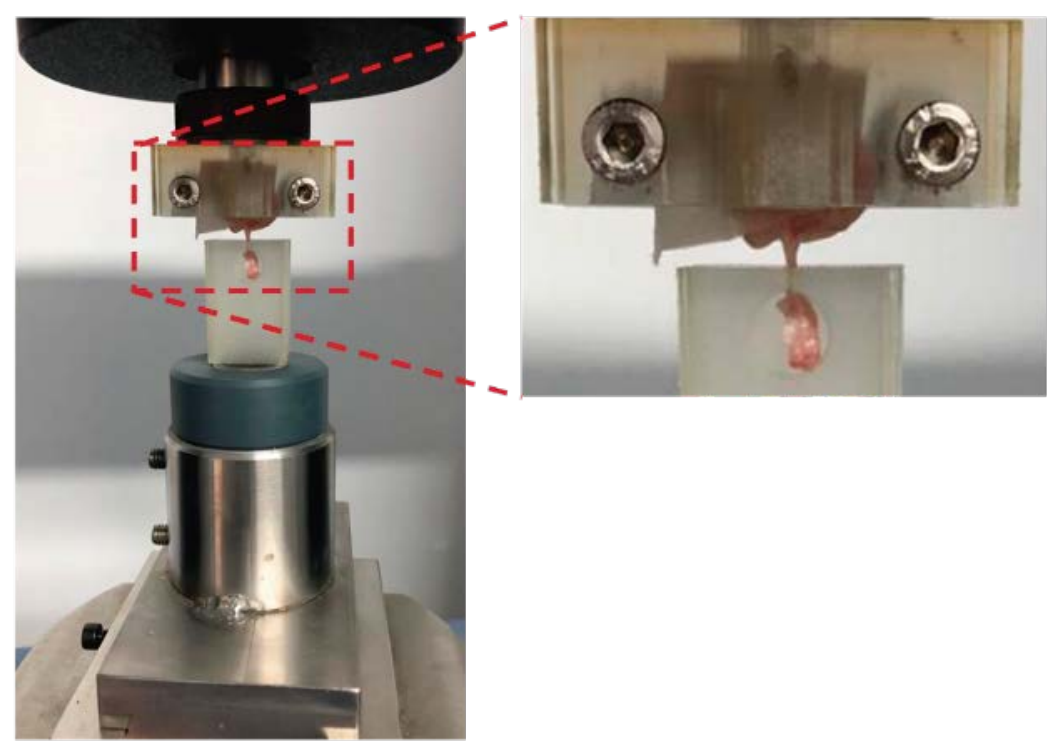


Figure 7-figure supplement 4
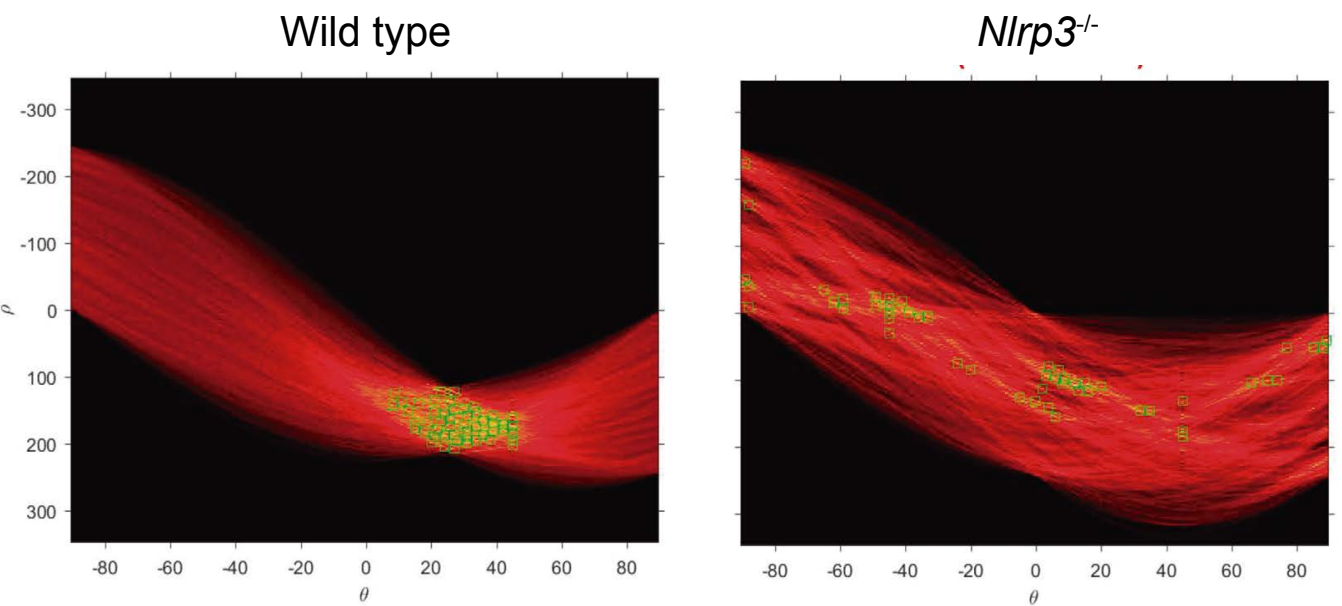